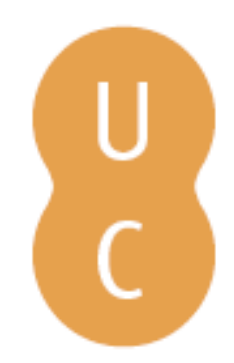

\title{
Rommalina
}

\section{Extração de fitoquímicos com fluidos pressurizados/supercríticos e impregnação destes em biomateriais}

\author{
Autor(es): $\quad$ Braga, Mara E. M.; Dias, Ana M. A.; Sousa, Hermínio C. de \\ Publicado por: Imprensa da Universidade de Coimbra \\ URL \\ persistente: URI:http://hdl.handle.net/10316.2/36925 \\ DOI: $\quad$ DOI:http://dx.doi.org/10.14195/978-989-26-0881-5_14 \\ Accessed : $\quad$ 26-Apr-2023 15:00:48
}

A navegação consulta e descarregamento dos títulos inseridos nas Bibliotecas Digitais UC Digitalis, UC Pombalina e UC Impactum, pressupõem a aceitação plena e sem reservas dos Termos e Condições de Uso destas Bibliotecas Digitais, disponíveis em https://digitalis.uc.pt/pt-pt/termos.

Conforme exposto nos referidos Termos e Condições de Uso, o descarregamento de títulos de acesso restrito requer uma licença válida de autorização devendo o utilizador aceder ao(s) documento(s) a partir de um endereço de IP da instituição detentora da supramencionada licença.

Ao utilizador é apenas permitido o descarregamento para uso pessoal, pelo que o emprego do(s) título(s) descarregado(s) para outro fim, designadamente comercial, carece de autorização do respetivo autor ou editor da obra.

Na medida em que todas as obras da UC Digitalis se encontram protegidas pelo Código do Direito de Autor e Direitos Conexos e demais legislação aplicável, toda a cópia, parcial ou total, deste documento, nos casos em que é legalmente admitida, deverá conter ou fazer-se acompanhar por este aviso.

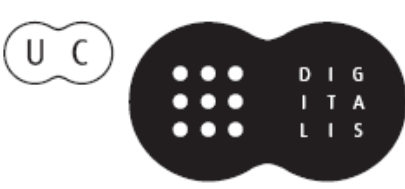


IOMATERIAIS APLICADOS AO DESENVOLVIMENTO DE SISTEMAS TERAPÊUTICOS AVANÇADOS

IOMATERIALES APLICADOS AL DISEÑO DE SISTEMAS TERAPÉUTICOS AVANZADOS

Hermínio C. de Sousa Mara E. M. Braga Alejandro Sosnik (editores) 


\section{CAPÍTULO 14. EXTRAÇÃO DE FITOQUÍMICOSCOM FLUIDOS SUB - E SUPERCRÍTICOS E IMPREGNAÇÃ O DESTES EM B I OMATERIAIS}

Mara E. M. Braga, Ana M. A. Dias, Hermínio C. de Sousa CIEPQPF, Departamento de Engenharia Química, FCTUC, Universidade de Coimbra, Rua Sílvio Lima, Pólo II - Pinhal de Marrocos, 3030-790 Coimbra, Portugal.

\section{Resumo:}

Neste capítulo são apresentadas as principais vantagens do uso da tecnologia supercrítica na obtenção de compostos ou frações bioativas a partir de diferentes matrizes vegetais que podem ter aplicações na indústria médico-farmacêutica (como fitoterápicos com as mais diversas ações terapêuticas), alimentar (como nutracêuticos, estabilizantes, aromas, pigmentos, espessantes, etc), cosmética (como agentes de coloração, aromas, óleos, protetores solares, etc) e na agricultura (como pesticidas naturais por exemplo). Tendo em consideração a enorme diversidade vegetal presente na natureza, é referida a importância dos estudos etnobotânicos no descobrimento de novos fitoquímicos e consequentemente nos avanços que tem sido conseguidos na prevenção e/ou tratamento de diversos tipos de doenças. Com o objetivo de otimizar a extração dos referidos compostos bioativos usando fluidos supercríticos apresentam-se as variáveis/estratégias de processo normalmente estudadas (densidade do solvente, uso de co-solvente, fracionameto, seleção da matriz vegetal e geometria do leito) assim como o seu efeito no rendimento e seletividade do processo para compostos/frações alvo, através de exemplos específicos de casos 
de estudo com diferentes matrizes vegetais (incluindo resíduos agro-industriais), nomeadamente a casca de pinheiro, o rizoma de açafrão, a baga de fruto de sabugueiro, a casca de semente de tara e as flores, caules e folhas de jambu. Apresentam-se ainda vantagens da integração dos processos de extração e impregnação/deposição com fluidos supercríticos no desenvolvimento de dispositivos médico-farmacêuticos para libertação controlada de fitofármacos, com exemplos de casos de sucesso já reportados na literatura.

Palavras-chave: extração de compostos bioativos; fitofármacos; impregnação/deposição de compostos bioativos; fluidos pressurizados e supercríticos; aplicações farmacêuticas e biomédicas.

\begin{abstract}
:
This chapter presents the main advantages of using supercritical fluid technology to extract bioactive compounds or bioactive fractions from different vegetal matrices and which may find applications in industries such as medical and pharmaceutical (as phytotherapics with diverse therapeutic actions), food (as nutraceuticals, stabilizers, flavors, pigments, thickeners, etc.), cosmetics (as coloring and flavoring agents, oils, UV-protectors, etc.) and agriculture (as natural pesticides for example). Given the enormous nature's biodiversity, this chapter highlights the importance of ethnobotanic studies in the discovery of new phytochemicals and consequent advances that have been achieved so far in the prevention and/or treatment of different kind of diseases. Several process variables/strategies that are usually studied in order to optimize the extraction of those bioactive compounds/fractions using supercritical fluids are described (solvent's density, use of co-solvent, fracionation, selection of plant matrix and bed geometry) as well as its effect on the yield and selectivity of the process for target compound/fractions, showing examples of case studies using different vegetal matrices (including agro-industrial residues) namely pine bark, turmeric rhizome, elderberry pomace, tara seed coat and flowers, stems and leaves of jambu. Finally, the advantages of using
\end{abstract}


the supercritical fluid technology to simultaneously extract bioactive compounds from vegetal matrices and impregnate/deposite those compounds into polymeric matrices are also described and presented (providing successful examples already reported in the literature) as an efficient procedure to develop medical and pharmaceutical devices for controlled release of phytochemicals.

Keywords: extraction of bioactive compounds; phytochemicals; impregnation/deposition of bioactive compounds; pressurized and supercritical fluids; biomedical and pharmaceutical applications. 


\section{Introdução}

\subsection{A importância dos fitoquímicos e sua utilização}

A busca de cuidados com a saúde mais eficazes, nomeadamente para o alívio de sintomas e a prevenção ou cura de doenças, remonta a tempos pré-históricos, com o descobrimento de moléculas como a morfina, a atropina, o quinino e a digoxina [1]. A obtenção de compostos naturais e suas aplicações nas áreas alimentar, cosmética, agricultura e médica (em formulações com pré-dosagem para a promoção da saúde e com propriedades terapêuticas para prevenção ou cura de doenças) data de muitos anos atrás, desde as civilizações Mesopotâmica, Egípcia e Chinesa.

A História relata o uso de formulações à base de plantas medicinais em todo o mundo antigo [2,3]. Escritos antigos, como por exemplo os textos médicos Anglo-Saxões do século $\mathrm{X}$, relatam o estudo e uso de plantas, descrevendo formulações à base de ervas envolvendo mais de 250 espécies de plantas, muitas das quais já testadas em relação à sua composição química e propriedades farmacológicas [3]. Alguns desses produtos naturais ainda são utilizados pela sociedade moderna, e de acordo com a Organização Mundial de Saúde (World Health Organization, WHO) cerca de $75 \%$ da população mundial ainda depende de medicamentos tradicionais de base natural para cuidado de saúde primário (em países Asiáticos e Africanos $80 \%$ da população depende da medicina tradicional para cuidados primários de saúde). Em muitos países desenvolvidos, entre 70 a $80 \%$ da população usa alguma forma de medicina alternativa ou complementar à convencional, como por exemplo a acupunctura. A Organização Mundial de Saúde reconhece a importância das espécies utilizadas como medicamentos pelos Ameríndios e recomenda o estudo e avaliação da sua eficácia através

de ensaios farmacológicos e toxicológicos. Nos últimos anos, a flora Americana [4] e Africana [5] têm sido estudadas por se reconhecer que há uma diversidade inexplorada nestas regiões, capaz de levar ao avanço da cura e tratamento de doenças através da fitoterapia. Os tratamentos 
à base de ervas são a forma mais popular da medicina tradicional, e são altamente lucrativos no mercado internacional. As receitas anuais na Europa Ocidental alcançaram US\$ 5 biliões entre 2003 e 2004. $\mathrm{Na}$ China a venda de produtos totalizou US\$ 14 biliões em 2005, enquanto no Brasil as receitas foram de US\$ 160 milhões em 2007 (WHO).

Muitos dos medicamentos utilizados na medicina desenvolvida nos países ocidentais têm por base a medicina tradicional, com mecanismos de ação identificados muito recentemente. O conhecimento destes mecanismos proporciona a descoberta de novos compostos bioativos, assim como o desenho de estruturas similares e posterior síntese [1].

Muitas das informações farmacológicas obtidas sobre plantas medicinais e alimentos funcionais são de base empírica e a seleção destas plantas está relacionada com as características cognitivas, fatores ecológicos e história cultural da população (como por exemplo o resultado de migrações populacionais). Como exemplo pode citar-se o caso de migrações da Turquia para a Alemanha que levaram à inserção na cultura local de 167 fitoterápicos (com uso de 79 espécies botânicas) e 115 preparações à base de plantas, assim como outros medicamentos à base de derivados de animais e minerais. Contudo, e embora a aculturação possa acontecer em caso de migração populacional, as comunidades acabam por manter registos de usos e costumes ancestrais que relacionam o uso de alimentos (alimentos funcionais) e medicamentos naturais com o seu bem-estar e saúde [6]. Um estudo etnofarmacológico realizado numa província do centro da Itália mostrou que nesta região o uso de plantas medicinais e alimentos funcionais na cultura local sobreviveu a gerações por esta província estar isolada geograficamente [7].

A busca de novas moléculas bioativas tem feito uso da etnobotânica e etnofarmacologia a nível mundial [8]. A Tabela 14.1 mostra vários estudos etnofarmacológicos realizados na última década, indicando a diversidade de espécies e substâncias com atividades farmacológicas encontradas em todo o mundo, independentemente de terem ou não comprovação clínica (apesar de a maior parte dos relatos indicarem aplicações médicas específicas). Desta forma, a flora e a diversidade natural tem um importante papel no descobrimento de novas moléculas com potencial para serem 
usadas na medicina moderna. Contudo esta enorme biodiversidade não se limita à descoberta de moléculas com atividade farmacológica para aplicações na área da saúde, mas também para diversas outras aplicações como suplementos alimentares [9], produtos cosméticos [10], assim como aplicações industriais como pesticidas naturais [11].

Os produtos de origem botânica são regulamentados de forma diferente nos estados membros da União Europeia, assim como nos demais países. Esta regulamentação está relacionada com as diferenças na utilização do produto, na aplicação cultural e histórica do mesmo e na base científica que suporta a utilização e a legislação local. A regulamentação tem sido revista na Europa, bem como os métodos atuais de avaliação da qualidade, eficácia e segurança, e há propostas para que os produtos de origem botânica sejam regulamentados em categorias como fitoterápicos ou nutracêuticos (alimentos funcionais) $[12,13]$. No caso dos nutracêuticos, e até ao ano de 2006, não havia regulamentação para o seu uso na União Europeia. As regras a serem aplicadas nestes produtos são numerosas pois são as mesmas que para os alimentos em geral. A regulamentação de nutracêuticos segundo critérios nutricionais e de promoção da saúde foram introduzidas na União Europeia em 2007. Era esperada a sua implementação em 2010 (alguns países da Europa já aplicam voluntariamente estes códigos) contudo, as avaliações científicas sobre a aplicação de nutracêuticos na saúde estão directamente dependentes de recomendações e critérios nutricionais específicos para cada produto [14], o que atrasa o processo de regulamentação e legislação.

A União Europeia tem legislado produtos para uso medicinal através da Traditional Herbal Medicinal Product Directive (THMPD), como alimento através da General Food Law Regulation (GFLR) 178/2002, o uso de espécies botânicas através da Food Supplements Directive (FSD) 2002/46/ EC e através das alegações de nutrição e saúde pela Nutrition and Health Claims Regulation (NHCR) e na adição de vitaminas e minerais e outras substâncias para alimentos (Addition of Vitamins and Minerals and Other Substances to foods Regulation, AVMOSR) adotadas em 2006 [15]. Além disso a legislação para alimentos dietéticos, suplementos alimentares ou novos alimentos pode ser aplicável a alimentos funcionais dependendo da natureza do produto e do seu uso [16]. 
As etapas e considerações necessárias para a introdução de um produto nutracêutico no mercado, e que vão desde a identificação da espécie botânica até estudos de eficácia e validação científica, foram descritas por Gulati et al [17]. O Center for Drug Evaluation and Research (CDER) da Food and Drug Administration (FDA) desenvolveu um guia para a indústria sobre a elaboração de produtos à base de espécies botânicas para fins médico-farmacêuticos, que com informação importante e abrangente desde regulamentação até estratégias de marketing para comercialização do produto natural [18].

O processo de seleção, identificação e aplicação final de um produto botânico é extenso, tal como descrito no diagrama geral de extração e separação de compostos bioativos para aplicações farmacêuticas, alimentar ou cosmética, apresentado na Figura 14.1. Além de longo, o processo apresenta custos elevados. Uma avaliação realizada pelo FDA em 2003 revelou que somente 21 produtos botânicos foram colocados no mercado no período de 1981 a 2002. De 877 novos fármacos desenvolvidos, 6\% eram compostos por produtos naturais, $27 \%$ eram derivados de produtos naturais e $16 \%$ eram medicamentos sintéticos desenvolvidos a partir de um modelo de um produto natural [19]. Verpoorte et al [1] também descreve que os custos de desenvolvimento de um novo fármaco podem chegar a valores que variam entre 800 a 1000 milhões de Euros, e para encontrar um novo fármaco são testados/estudados de 10.000 a 100.000 compostos, com uma média de 15 anos para o desenvolvimento deste processo.

Um exemplo de estudo foi registrado no Brasil (país com grande biodiversidade), com foco no uso de plantas medicinais com efeitos no sistema nervoso central utilizadas entre os séculos XVI e XIX. Das trinta e quatro plantas estudadas, 13 foram registadas em estudos etnofarmacológicos em comunidades modernas Brasileiras e 16 espécies foram estudadas fitoquimicamente. Somente oito espécies foram objeto de estudos farmacológicos na altura da publicação, sendo que seis tiveram um pedido de patente. Estes resultados revelam o potencial de aplicação das plantas com atividades farmacológicas e o atual estado da investigação de moléculas bioativas para a indústria farmacêutica no contexto Brasileiro [20], mostrando que de um universo de 34 espécies quase 18\% foram propostas para se tornarem medicamentos de acordo com os pedidos de patentes indicados. 
Tabela 14.1. Exemplos de estudos realizados em vários países e regiões do globo sobre espécies endémicas e exóticas com indicações médico-farmacêuticas.

\begin{tabular}{|c|c|c|c|}
\hline Países e Regiões & Espécies originárias & Indicações & Referência \\
\hline África do Sul & 33 espécies vegetais & $\begin{array}{l}\text { Doenças infeciosas transmitidas } \\
\text { sexualmente como gonorréia, } \\
\text { feridas, verrugas e sífilis }\end{array}$ & [21] \\
\hline África do Sul & 90 espécies vegetais & Várias & [5] \\
\hline Alemanha & 221 espécies vegetais & Epilepsia & {$[22]$} \\
\hline Argentina & 48 espécies vegetais & Saúde infanto-maternal & [23] \\
\hline Argentina e Chile & 22 espécies vegetais & Tuberculose & [24] \\
\hline Bósnia e Herzegovina & 228 espécies vegetais & Várias & [25] \\
\hline Brasil & 34 espécies vegetais & $\begin{array}{c}\text { Doenças do sistema nervoso } \\
\text { central }\end{array}$ & [26] \\
\hline $\begin{array}{l}\text { Brasil (Monges Benedi- } \\
\text { tinos) }\end{array}$ & 67 espécies vegetais & Várias & [27] \\
\hline Coreia, China e Japão & 20 espécies vegetais & Problemas no sistema vascular & {$[28]$} \\
\hline $\begin{array}{l}\text { Equador (grupos } \\
\text { étnicos: Loja e Zamora- } \\
\text {-Chinchipe) }\end{array}$ & 275 espécies vegetais & Várias & [29] \\
\hline Europa e Estados Unidos & $\begin{array}{l}\text { Hypericum perfora- } \\
\text { tum } \mathrm{L} \text {. }\end{array}$ & Depressão & [30] \\
\hline $\begin{array}{l}\text { Espanha (Granada, An- } \\
\text { daluzia) }\end{array}$ & 26 espécies animais & Várias & [31] \\
\hline Índia & 577 espécies & $\begin{array}{c}\text { Regulação da fertilidade em } \\
\text { mulheres considerando o efeito } \\
\text { abortivo, contraceptivo, emenago- } \\
\text { go e esterilizante. }\end{array}$ & [32] \\
\hline Índia & 64 espécies vegetais & Cortes, feridas e queimaduras & [37] \\
\hline Índia & 40 espécies vegetais & Diabetes & [34] \\
\hline Itália & Ruta spp. & $\begin{array}{l}\text { Abortivo e emenagogo, além de } \\
\text { doenças pulmonares }\end{array}$ & [35] \\
\hline Mediterrâneo & $\begin{array}{l}439 \text { espécies ve- } \\
\text { getais, animais e } \\
\text { minerais }\end{array}$ & Várias & [8] \\
\hline $\begin{array}{l}\text { Mediterrâneo: Albânia, Ar- } \\
\text { gélia, Chipre, Egipto, Itá- } \\
\text { lia, Marrocos e Espanha }\end{array}$ & 985 espécies vegetais & Várias & [36] \\
\hline $\begin{array}{l}\text { México (grupos étnicos: } \\
\text { Mixe e Popoluca) }\end{array}$ & 15 espécies vegetais & Várias & [37] \\
\hline Mongólia & 152 espécies vegetais & $\begin{array}{l}\text { Doenças gastrointestinais, derma- } \\
\text { tológicas e cardiovasculares }\end{array}$ & [38] \\
\hline Peru & 203 espécies vegetais & Malária e leishmaniose & [39] \\
\hline Peru & 55 espécies vegetais & Vários & [40] \\
\hline Rússia & 17 espécies vegetais & Câncer e antitrombina & [41] \\
\hline Sérvia & 69 espécies vegetais & $\begin{array}{l}\text { Doenças gastrointestinais, derma- } \\
\text { tológicas e problemas respiratórios }\end{array}$ & {$[42]$} \\
\hline Tailândia & 79 espécies vegetais & Saúde feminina & [43] \\
\hline Tailândia & 11 espécies vegetais & Herpes vírus tipo 1 (HSV-1) & [44] \\
\hline Tailândia & 38 espécies vegetais & $\begin{array}{c}\text { Hemorragia interna provocada } \\
\text { por } E \text {. coli } 0157: \mathrm{H} 7\end{array}$ & {$[45]$} \\
\hline Turquia & 81 espécies vegetais & Várias & [46] \\
\hline Vietname & 14 espécies vegetais & Malária & [47] \\
\hline Europa e Estados Unidos & $\begin{array}{l}\text { Hypericum perfora- } \\
\text { tum } \mathrm{L} .\end{array}$ & Depressão & [30] \\
\hline $\begin{array}{l}\text { Mediterrâneo (Albânia, Ar- } \\
\text { gélia, Chipre, Egipto, Itália, } \\
\text { Marrocos e Espanha) }\end{array}$ & 985 espécies vegetais & Várias & [36] \\
\hline
\end{tabular}


Muitos dos compostos já isolados têm grande interesse na indústria alimentar e/ou médico-farmacêutica como por exemplo as antocianinas e carotenóides, ou compostos mais voláteis como a cânfora, o ácido carnosóico ou o álcool perílico, entre outros. Talansier et al [48] estudou a extração de compostos bioativos (khusimol, isovalencenol, ácido zizanóico e vetivona) a partir de raízes de vetiver (Vetiveria zizanioides) mostrando que estes têm aplicações na indústria cosmética, mas também como aditivos alimentares na adição de aromas em bebidas, ou para aplicações médico-farmacêuticas no tratamento de comportamentos relacionados com demência, aumentando a função cognitiva e agilidade mental.

Após a obtenção do produto este deve estar devidamente caracterizado e identificado para garantir ao consumidor a distinção entre produto medicinal à base de produtos naturais com finalidade terapêutica, e suplementos alimentares à base de plantas com a finalidade de promover a saúde. Coppens et al [15] sugere um formato simples para resumir as informações sobre um determinado produto natural e seus benefícios para a saúde (Tabela 14.2). 


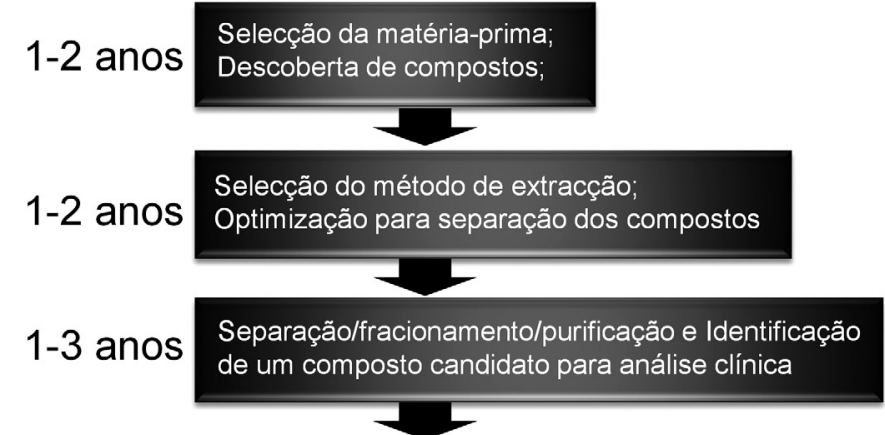

Registro da Investigação de um novo composto bioactivo; Aplicação de patente

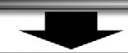

Ensaios não-clínicos:

Testes in vivo e in vivo

"Good laboratory practice" (GLP)

3-6 anos Estudos clínicos (fase I-III)

"Good clinical practices" (GCPs)

Fase I: testes de segurança, niveis de dosagens

(20-100 voluntários saudáveis);

Fase II: estudos de eficácia terapêutica;

Fase III: verificação da eficácia, efeitos adversos

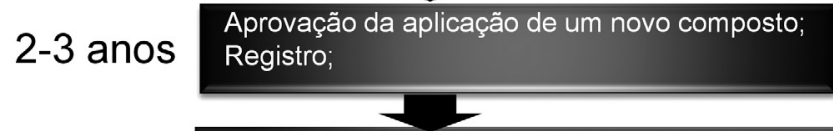

Aumento de escala e produção: "Good Manufacturing Practice" (GMP) Regulamentação, questões económicas e de propaganda

Figura 14.1. Desenvolvimento de um novo fármaco à base de produto natural (baseado em Verpoorte et al [1], Braga et al [49] e Newman et al [19]).

\subsection{Obtenção de compostos e frações naturais}

Os compostos bioativos podem ser obtidos por vários métodos de extração sólido-líquido, líquido-líquido ou utilizando um solvente em estado supercrítico. Após a obtenção do extrato é importante identificar a necessidade de fracionamento e/ou purificação para a sua utilização. Neste sentido muitos métodos são otimizados para obter não somente o máximo rendimento, mas também para atingirem uma seletividade tal que a fração obtida contenha a molécula ou moléculas com ação pretendida. 
Tabela 14.2. Resumo de algumas informações necessárias para a identificação de um fitofármaco.

\begin{tabular}{l|l|l|l|l|l}
\hline $\begin{array}{l}\text { Alimento ou com- } \\
\text { ponente de um } \\
\text { alimento/composto } \\
\text { bioactivo }\end{array}$ & Indicação & Dosagem & $\begin{array}{l}\text { Natureza da } \\
\text { evidência }\end{array}$ & $\begin{array}{l}\text { Nível de } \\
\text { evidência }\end{array}$ & $\begin{array}{l}\text { Exemplos de } \\
\text { resultados }\end{array}$ \\
\hline $\begin{array}{l}\text { Mirtilo b } \\
\text { (proantocianidinas) }\end{array}$ & $\begin{array}{l}\text { Trato uri- } \\
\text { nário }\end{array}$ & $\begin{array}{l}200 \mathrm{mg} / \mathrm{dia} \\
\text { de sumo } \\
\text { de mirtilo }\end{array}$ & $\begin{array}{l}\text { Experiência a } \\
\text { longo prazo; } \\
\text { reduzido } \\
\text { número de } \\
\text { casos clínicos }\end{array}$ & Provável & $\begin{array}{l}\text { Mantém a } \\
\text { saúde do trato } \\
\text { urinário }\end{array}$ \\
\hline $\begin{array}{l}\text { Alho } \\
\text { (compostos organo- } \\
\text {-sulfurosos) }\end{array}$ & $\begin{array}{l}\text { Coração e } \\
\text { sistema cir- } \\
\text { culatório }\end{array}$ & $\begin{array}{l}600-900 \\
\text { mg/dia }\end{array}$ & $\begin{array}{l}\text { Experiência a } \\
\text { longo prazo; } \\
\text { casos clínicos }\end{array}$ & Provável & $\begin{array}{l}\text { e do sistema } \\
\text { circulatório } \\
\text { (em relação ao } \\
\text { colesterol total }\end{array}$ \\
\hline $\begin{array}{l}\text { Chá verde } \\
\text { (catequinas) }\end{array}$ & Cancro & $\begin{array}{l}\text { Lescont) } \\
\text { cido }\end{array}$ & $\begin{array}{l}\text { Utilização } \\
\text { generalizada }\end{array}$ & $\begin{array}{l}\text { Possível/ } \\
\text { provável }\end{array}$ & $\begin{array}{l}\text { Redução de } \\
\text { riscos de certos } \\
\text { tipos de câncer }\end{array}$ \\
\hline
\end{tabular}

a Os níveis de evidência são temporários e não são baseados numa revisão científica sistemática.

b A "Agence Française de Sécurité Sanitaire des Aliments" (AFSSA) tem aprovado o uso do mirtilo. Baseado em Coppens et al [15].

Assim, neste capítulo pretende-se fazer uma breve descrição de parte dos trabalhos de investigação que o Laboratório de Processos Verdes e Sustentáveis (GSP do inglês Green and Sustainable Processes Laboratory), do Centro de Investigação em Engenharia dos Processos Químicos e dos Produtos da Floresta do Departamento de Engenharia Química da Universidade de Coimbra tem desenvolvido nos últimos anos. Pretende-se enfatizar os trabalhos que visam a otimização da metodologia de extração usando fluidos supercríticos para a obtenção de fitoquímicos a partir de fontes renováveis, como por exemplo matérias-primas vegetais e resíduos agro-industriais. Também será apresentado o desenvolvimento de produtos para aplicações médico-farmacêuticas (nomeadamente curativos medicados para tratamento de feridas) com base na ação de fitoquímicos de base natural, alguns dos quais foram extraídos e impregnados usando a tecnologia supercrítica em ambos os processos. 


\subsubsection{Extração com dióxido de carbono supercrítico $\left(\operatorname{scCO}_{2}\right)$}

Com o objetivo de otimizar o processo de separação/fracionamento e isolamento dos compostos bioativos de interesse, as técnicas de extração e as tecnologias desenvolvidas para aumentar a eficiência dos processos de extração/separação têm sido alvo de intenso estudo. A combinação de técnicas, mistura de solventes ou solventes alternativos são constantemente apresentados na literatura, assim como o uso de aditivos e novos equipamentos que promovem máxima eficiência [49].

O dióxido de carbono é um solvente considerado seguro, limpo, não inflamável, não tóxico, de relativo baixo custo, ambientalmente aceite, não-poluente em determinadas concentrações e que pode ser reciclado. Além disso duas das principais vantagens do uso do dióxido de carbono em estado supercrítico $\left(\mathrm{scCO}_{2}\right)$ são o facto de que, sendo um solvente ligeiramente apolar, favorece a extração de compostos apolares (pela sua afinidade com estes) substituindo os solventes orgânicos normalmente usados e que apresentam maior toxicidade como o hexano; outra vantagem é que a manipulação do estado físico do solvente permite que este seja eliminado do sistema de extração em estado gasoso, ficando o produto final livre de solvente, evitando assim etapas posteriores de separação do soluto extraído [50].

Neste sentido a tecnologia que utiliza $\mathrm{CO}_{2}$ como fluido supercrítico ou pressurizado tem mostrado vantagens em relação às técnicas convencionais uma vez que permite o processamento a baixas temperaturas, evitando a degradação de compostos termolábeis, e a ocorrência de ligeira acidificação da matéria-prima no leito de extração, através da formação de ácido carbónico, que pode potenciar a solubilidade de alguns compostos como as antocianinas [51] ou ainda levar à redução da carga microbiana do meio [52]. As vantagens da tecnologia supercrítica estendem-se ainda à obtenção de compostos não sintetizáveis de alto valor agregado, de compostos que possuam alta atividade biológica com a mínima concentração, moléculas instáveis térmica ou enzimaticamente, ou ainda frações que não podem conter traços de solventes. 
A tecnologia permite ainda o uso de co-solventes, principalmente para promover a extração de compostos com maior polaridade, atendendo à baixa polaridade do $\mathrm{scCO}_{2}$ anteriormente referida. Os co-solventes mais comummente usados são o etanol (EtOH) e/ou a água $\left(\mathrm{H}_{2} \mathrm{O}\right)$, que podem ser usados sem restrições, principalmente para aplicações nas áreas farmacêutica, alimentar e cosmética.

Com o objetivo de reduzir as etapas de seleção e obtenção de compostos bioativos, a otimização dos processos de extração tornam possível o fracionamento de um extrato durante o próprio processo de extração, evitando etapas posteriores exaustivas de purificação de compostos. As características dos fluidos supercríticos destacam-se por possuírem propriedades intermédias às dos líquidos e dos gases, promovendo a transferência de massa entre a matriz vegetal e o solvente. Além disso, essas propriedades podem ser controladas com a variação da pressão e temperatura de processo (Figura 14.2), e consequentemente da densidade do solvente.

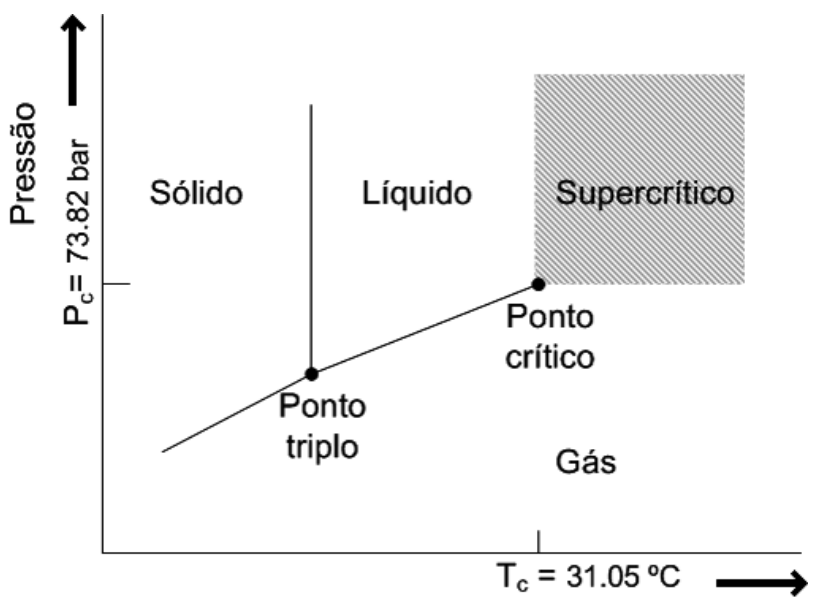

Temperatura

Figura 14.2. Diagrama de fases do dióxido de carbono supercrítico.

Além da otimização das propriedades dos solventes, através da variação da temperatura e pressão de processamento, diferentes gradientes podem ser realizados para mudar a densidade do solvente e 
consequentemente a solubilidade de compostos diferenciados neste. O uso de separadores é comum em equipamentos mais versáteis, contudo outras variáveis podem ser alteradas como o caudal do solvente, o uso de um co-solvente ou de uma mistura de solventes pressurizados, ou ainda a variação sequencial de solventes no sistema de extração, levando ao fracionamento do extrato de acordo com a polaridade/afinidade com o solvente utilizado. Diferentes geometrias de leito podem ainda ser utilizadas, assim como a agitação do mesmo ou extração em contra-corrente, extração estática e/ou em contínuo [53]. Os mecanismos de transportes que envolvem este processo são semelhantes aos processos de extração convencionais, sendo o transporte através da matriz sólida do soluto desejado dependente da distribuição inicial dos compostos extratáveis, da distribuição do tamanho de partículas no leito de extração, da geometria do leito de partículas, da presença ou não de agitação no processo [53]. Assim, para cada matriz a extrair as variáveis de processo devem ser optimizadas, uma vez que a composição inicial da matéria-prima, assim como a geometria e tamanho da partícula a ser extraída vão ditar os mecanismos de transferência de massa.

Finalmente, e em relação aos custos de energia associados ao processo de extração supercrítica, estes podem até ser menores que os custos associados aos métodos tradicionais de extração com solventes orgânicos [50]. Claramente o custo da matéria-prima e do produto final influenciarão o custo do processo, e neste sentido já existem vários estudos que discutem a viabilidade económica do processo para produtos naturais [54-56].

\subsubsection{Estudo das variáveis de extração}

Devido à sua complexidade, a otimização de processos de extração requer a análise prévia de um conjunto de diferentes parâmetros que vão desde a identificação: de potenciais origens naturais dos extratos/compostos-alvo de interesse; de rendimento e seletividade 
necessários de acordo com os potenciais produtos/aplicações finais; da estabilidade térmica e química dos extratos; de questões económicas e de mercado; da legislação envolvida (principalmente no caso de aplicações nas áreas alimentar, cosmética e farmacêutica) até questões relacionadas com o aumento de escala e possíveis problemas de produção/separação/purificação adicionais associados. Estes tópicos ajudam a definir a matéria-prima mais apropriada para ser extraída (e necessidade de pré-tratamento), a seleção de solventes mais apropriados (em termos de propriedades físico-químicas, pureza/composição e os riscos potenciais e toxicidade) e/ou a metodologia e condições operacionais de extração mais eficientes para cada caso em particular. Uma vez definidos os extratos/compostos-alvo e questões relevantes relativas à sua extração, é também necessário identificar outros problemas físicos, químicos e de engenharia (por exemplo, o equilíbrio de fases soluto(s)/solvente(s) e questões de transferência de massa), a fim de otimizar a metodologia de extração (em termos de rendimento de extração e seletividade do composto alvo) e evitar (ou reduzir) o número de etapas de separação e purificação adicionais. Todos estes fatores são igualmente dependentes das condições de processamento (tais como o tempo de processamento, a composição, a temperatura, a pressão, a razão de sólido/solvente, taxa de fluxo, e outros modos de funcionamento e de contato) o que aumenta significativamente a complexidade destes processos. Finalmente é importante considerar que, para a obtenção de um composto alvo específico, é possível usar matérias-primas vegetais diferentes assim como diferentes solventes e metodologias de extração. Assim, e embora seja possível transpor algumas informações úteis adquiridas a partir de sistemas de extração já estudadas, cada novo sistema deve ser sempre considerado como único e, portanto, estudado, definido e desenvolvido de acordo com essa premissa.

Com esta ideia em mente, apresentam-se em seguida alguns dos parâmetros mais importantes a considerar na otimização de processos de extração assim como o efeito da sua variação na obtenção de compostos bioativos a partir de diferentes matrizes vegetais. 


\subsubsection{Estudo das condições ótimas de pressão e temperatura de processamento}

É possível otimizar o processo de extração com $\mathrm{scCO}_{2}$ para a obtenção do máximo rendimento dos compostos de interesse se for conhecida a solubilidade desses compostos puros em $\mathrm{scCO}_{2}$. Com o objetivo de otimizar as condições experimentais de extração de limoneno e carvona a partir de folhas de lipia (Lippia alba), os diagramas de equilíbrio de fases para cada sistema binário foram modelados com uma equação de estado cúbica (Peng-Robinson) [57]. A literatura descreve os extratos de L. alba como eficazes no tratamento de doenças do sistema respiratório, digestivo e neuro degenerativas como Alzheimer. Depois de identificadas as melhores condições para aumentar a solubilidade destes compostos em $\mathrm{scCO}_{2}$, estas foram utilizadas para o processo de extração comprovando que pressões e temperaturas baixas melhoram o rendimento para a carvona $(\sim 80$ bar e $313 \mathrm{~K})$ enquanto condições mais elevadas de pressão e temperatura aumentam a solubilidade do limoneno ( 120 bar e $323 \mathrm{~K})$, tal como comprovado pela análise quantitativa dos compostos analisados por CG. Este trabalho apresenta a importância do estudo teórico preliminar, que pode reduzir significativamente os tempo de ensaios em laboratório, ainda que tenha que ser considerada a complexidade da matriz vegetal e o fato de o estudo teórico envolver apenas o composto de interesse puro.

\subsubsection{Estudo do fracionamento do extrato: efeito do co-solvente e} do caudal de solvente no rendimento de extração

O fracionamento durante o processo de extração tem-se tornado uma prática comum pois permite reduzir etapas posteriores de separação/ purificação do extrato com solventes orgânicos, obtendo-se frações enriquecidas no composto de interesse como produto final. Neste sentido alguns autores têm realizado extração fracionada em equipamentos com ciclones/coletores, ou através da alteração de solventes 
(tipo e quantidade de solvente), ao longo do processo de extração. A vantagem do uso de um equipamento simples sem ciclones/coletores é ter apenas um sistema de recolha de extratos e uma única linha de controle do processo. Os extratos podem ser extraídos primeiramente com o solvente mais apolar como o $\mathrm{scCO}_{2}$, extraindo compostos mais voláteis, lípidos e algumas ceras. Sequencialmente, no mesmo leito onde as partículas foram deslipidificadas, é inserido um segundo solvente (ou co-solvente), que extrai compostos mais polares e de maior massa molecular. Nas aplicações alimentares e farmacêuticas a conveniência do uso da água e etanol reflete-se na facilidade de remoção, não havendo riscos de toxicidade por existirem traços destes solventes no produto final.

Um estudo do efeito de diferentes co-solventes (e suas misturas) no rendimento e seletividade de extratos obtidos a partir de rizomas de curcuma (Curcuma longa) foi realizado por forma a otimizar a extração de curcuminóides, cuja literatura relacionada indica apresentarem atividade anti-mutagênica e anti-carcinogénica [58]. Os curcuminóides são carotenóides com características polares, sendo necessário a utilização de um co-solvente para alterar ligeiramente a polaridade do $\mathrm{CO}_{2}$ e aumentar o rendimento de extração para estes compostos. Nesta proposta foram utilizados álcoois como o etanol e o isopropanol e a mistura destes (em proporções iguais), todos numa proporção de $6 \%$ em relação ao $\mathrm{CO}_{2}$. Foram ainda estudadas duas condições de pressão de processamento dos rizomas (200 e 300 bar). Como os curcuminóides e seus derivados possuem massa molar entre 300 e $370 \mathrm{~g} / \mathrm{mol}$, o uso de um co-solvente em maior proporção e condições mais elevadas de pressão (dentro das condições usadas para compostos naturais) são necessárias. Assim, o maior rendimento de extrato foi obtido operando a 300 bar, usando como co-solvente a mistura etanol/isopropanol a $16 \%$ (molar em relação ao $\mathrm{CO}_{2}$ ) e baixo caudal $\left(\sim 1 \times 10^{-5} \mathrm{~kg} / \mathrm{s}\right)$ para aumentar o tempo de residência do solvente no leito, e consequentemente o contacto com a matéria-prima, proporcionando e aumentando a solubilidade dos compostos de interesse (Figura 14.3). 


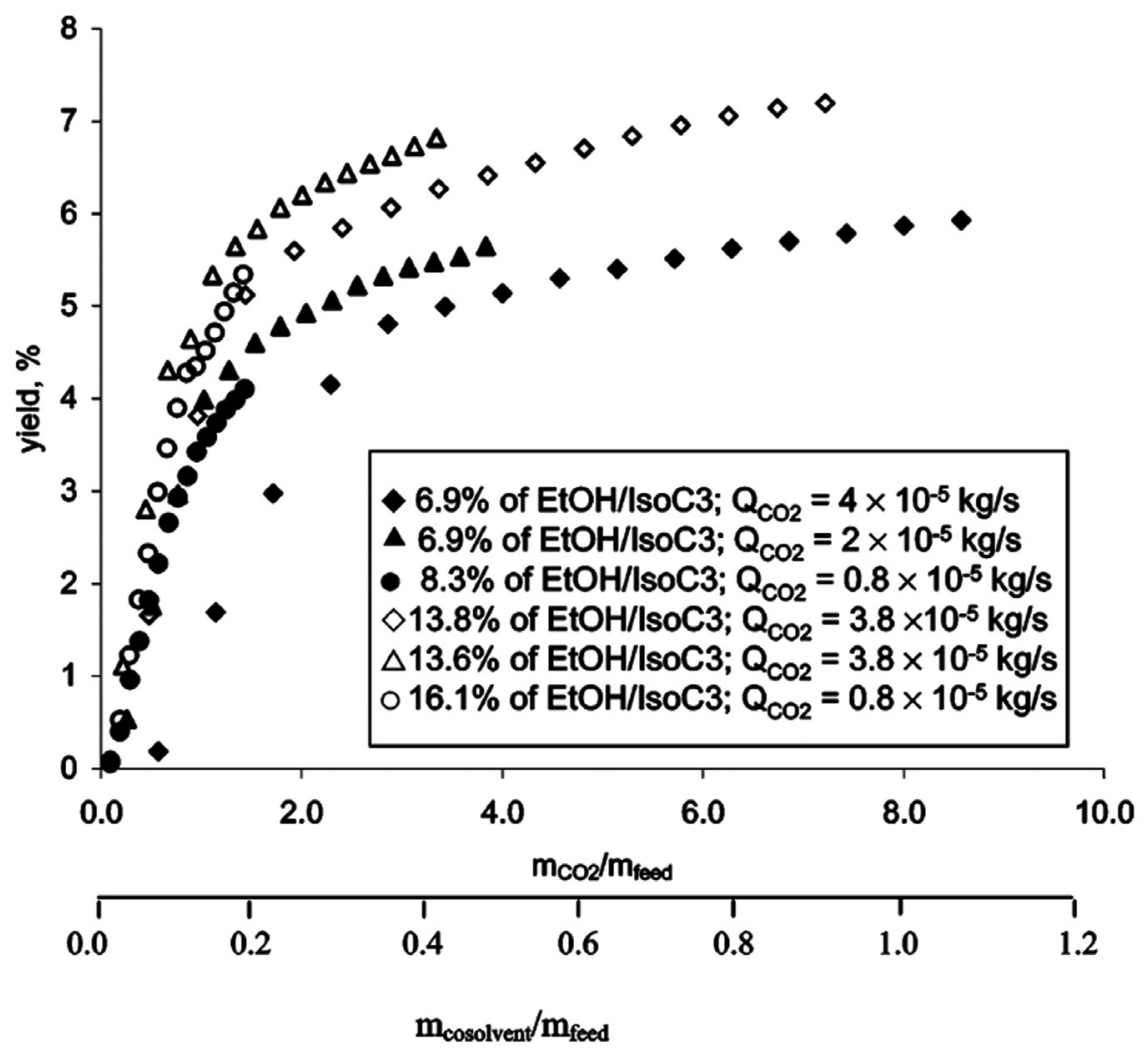

Figura 14.3. Curvas globais de extração de C. longa usando várias condições de solventes e caudais a 300 bar e $30^{\circ} \mathrm{C}$ [Braga et al, com permissão da ACS [53]].

A fração leve do extrato de curcuma, composta maioritariamente por compostos da família das atlantonas e turmeronas, apesar de apresentar baixa atividade antioxidante, apresenta citoxicidade seletiva para as células de cancro de ovário e mama e para células de mama com resistência a múltiplos fármacos, assim como atividade citostática para as células de pulmão [58]. A relação da composição dos extratos com as suas atividades não foi diretamente analisada, mas o extrato obtido nestas condições, composto por uma mistura rica em compostos mais voláteis (como as turmeronas e atlantonas) e curcuminóides, categorizam os extratos de curcuma como um potencial agente para tratamentos na área da oncologia (Figura 14.4). 


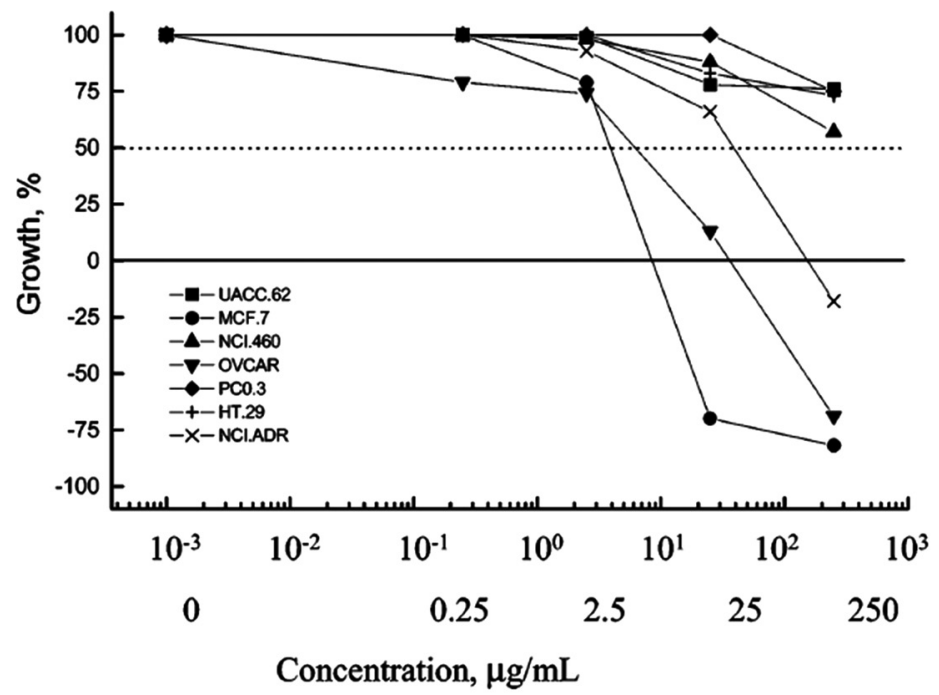

Figura 14.4. Atividade anti carcinogénica para linhagens de células cancerosas para óleo essencial de C. longa: UACC.62 (melanoma), MCF.7 (mama), NCI.460 (pulmão), OVCAR (ovário), PC0.3 (próstata), HT.29 (cólon), e NCI.ADR (mama expressando fenótipo de resistência a múltiplas drogas) [Braga et al, com permissão da ACS [58]].

Como exemplo da importância do fracionamento no processo de extração, refere-se a obtenção de extratos a partir da casca de pinheiro (Pinus pinaster), com elevado teor de compostos com atividade antioxidante, como catequinas e epicatequinas, visando valorizar um importante resíduo da indústria madeireira em Portugal. O fracionamento consistiu na realização de uma primeira etapa usando apenas $\mathrm{scCO}_{2}$ puro como solvente, até máxima extração do leito, e uma segunda etapa com uma mistura de $\mathrm{scCO}_{2}$ e $10 \%$ (v/v) de etanol (nesta composição mantem-se o estado supercrítico do solvente) [59]. Este trabalho mostra que os extratos obtidos a partir das cinéticas de extração sequenciais (Figure 14.5), apresentam atividades antioxidantes distintas para as frações obtidas: para os extratos mais apolares (obtidos somente $\mathrm{com} \mathrm{scCO}_{2}$ ) a atividade antioxidante variou entre 30 e $60 \%$ e para os extratos mais polares (obtidos com 10\% de etanol) os extratos apresentaram atividades antioxidantes entre 60 e 90\% (Figura 14.6). Estes resultados indicam que o fracionamento é necessário se o objetivo é obter como produto final uma fração enriquecida com compostos antioxidantes [59]. 
Num segundo estudo, com a mesma matriz vegetal (casca de pinheiro), foi estudado não só o efeito do fracionamento mas também da variação do caudal de solvente por forma a identificar as condições que favorecem a extração de procianidinas a partir desta matriz vegetal. As procianidinas têm recebido muita atenção nos últimos anos, nas áreas de nutrição e medicina, devido às suas atividades biológicas, nomeadamente anti-bacteriana, anti-viral, anti-carcinogénica, anti-inflamatória e de prevenção de doenças do sistema cardiovascular. Atualmente já existem produtos no mercado à base de extrato de casca do pinheiro, sendo o mais conhecido o Pycnogenol ${ }^{\circledR}$, o qual é vendido em todo o mundo como suplemento alimentar ou como medicamento à base de ervas.

Os resultados obtidos com este trabalho mostraram que, no caso de haver fracionamento, o segundo extrato recolhido ( $2^{a}$ etapa com $\mathrm{scCO}_{2}$ e EtOH) após a deslipidificação do extrato ( $1^{\mathrm{a}}$ etapa $\operatorname{com} \mathrm{scCO}_{2}$ ), apresentou uma quantidade superior ao dobro de compostos fenólicos e três vezes mais o teor de procianidinas, para o maior caudal estudado [60]. Tal como no estudo anterior, o maior rendimento de extrato foi obtido com o menor caudal, independentemente de haver ou não fracionamento, devido ao aumento do tempo de contato do solvente com a matriz vegetal. Considerando que o solvente está homogeneamente disperso no leito, a extração embora mais lenta, atinge o seu máximo na razão de solvente/sólido de 300 (razão mássica), confirmando que o tempo de contacto do solvente com a matriz vegetal é muito importante para a transferência de massa, sendo neste caso o factor limitante do processo (Figura 14.7). 


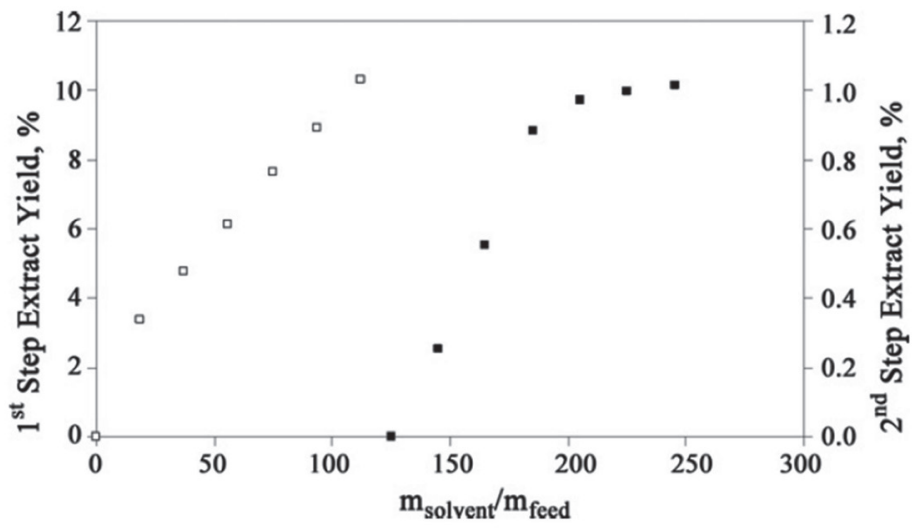

Figura 14.5. Cinéticas de extração de casca de pinheiro. Ensaios realizados a $40^{\circ} \mathrm{C}$ e $20 \mathrm{MPa}$ ( $\square$ ) $1^{\mathrm{a}}$ etapa com $\mathrm{CO}_{2}$ e (匹) $2^{\mathrm{a}}$ etapa $\operatorname{com} \mathrm{CO}_{2}+\mathrm{EtOH}(10 \%)$ [Braga et al, com permissão da Elsevier [59]].
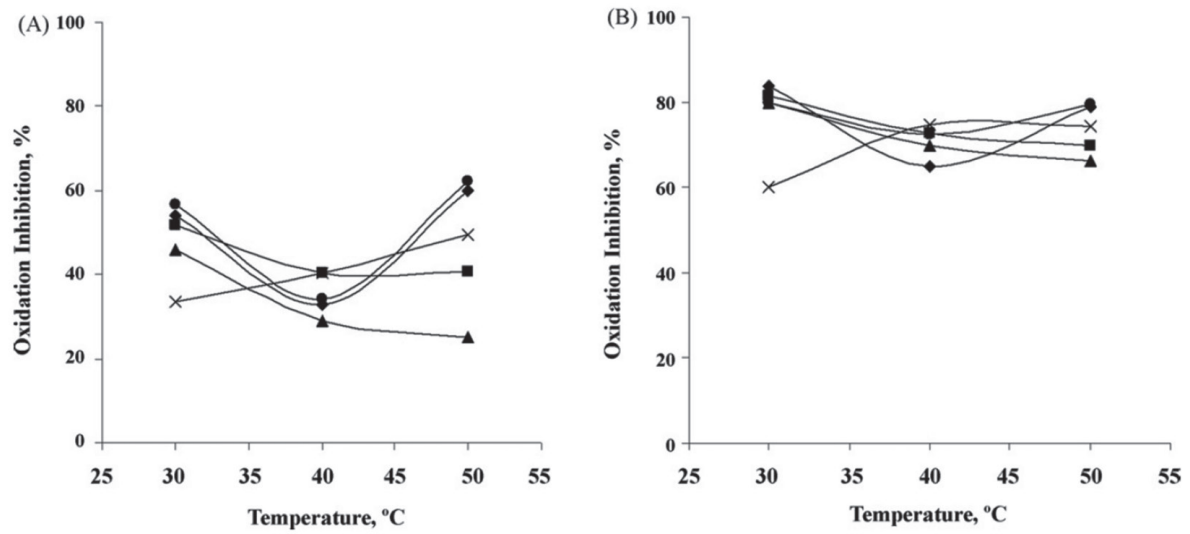

Figura 14.6. Perfis de inibição da oxidação dos extratos de casca de pinheiro (obtidos depois de $3 \mathrm{~h}$ de inibição). $1^{\mathrm{a}}$ etapa só $\operatorname{com} \mathrm{scCO}_{2}$ (A) e $2^{\mathrm{a}}$ etapa com mistura de $\mathrm{scCO}_{2}+\mathrm{EtOH}(10 \%, \mathrm{v} / \mathrm{v})(\mathrm{B})(\diamond) 10 \mathrm{MPa}$; (ロ) $15 \mathrm{MPa}$; (४) $20 \mathrm{MPa}$;

(•) $25 \mathrm{MPa}$; (×) $30 \mathrm{MPa}$ [Braga et al, com permissão da Elsevier [59]].

No caso da extração não-fracionada foi estudado o aumento do teor de co-solvente, obtendo-se desta forma uma mistura de solvente heterogénea pressurizada. Os teores de etanol utilizados foram 30, 50, 70 e $90 \%(\mathrm{v} / \mathrm{v})$ e os resultados mostram uma tendência de crescimento da atividade antioxidante quando se aumenta o teor de etanol, atingindo-se 
o máximo em $70 \%$, com valores de atividade antioxidante entre 70 e $80 \%$ até às primeiras $3 \mathrm{~h}$ de análise. O decréscimo da atividade observada para os extratos obtidos com 90\% de etanol deve-se provavelmente à extração de compostos indesejáveis devido ao alto teor de etanol usado. Os perfis cromatográficos dos diferentes extratos obtidos confirmam a diferença na composição química consoante a proporção do solvente utilizado [60].

Por comparação dos perfis cromatográficos é possível concluir que diferentes composições de extrato são obtidas para as diferentes condições de fracionamento e caudais de solventes estudados. Embora os perfis apresentem semelhanças, verifica-se que o fracionamento aumentou o rendimento de extração, promovida pelo aumento de concentração de compostos de interesse na matriz após a deslipidificação da mesma (Figura 14.8).

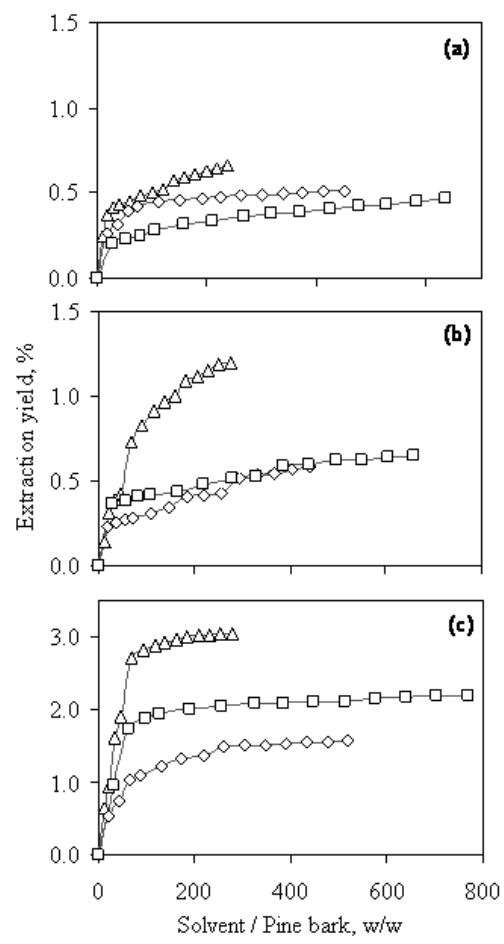

Figura 14.7. Curvas de extração de casca de pinheiro marítimo utilizando três diferentes caudais ( $\Delta$ baixo; $\Delta$ médio; $\square$ alto): (a) $1^{\text {a }}$ etapa $\operatorname{scCO}_{2}-323 \mathrm{~K}, \sim 20$ $\mathrm{MPa}$; (b) $2^{\mathrm{a}}$ etapa $\mathrm{scCO}_{2}: \mathrm{EtOH}(90: 10$, v/v) - $303 \mathrm{~K}, \sim 25 \mathrm{MPa}$; (c) Sem fracionamento e usando como solvente uma mistura de $\mathrm{scCO}_{2}$ : $\mathrm{EtOH}(90: 10, \mathrm{v} / \mathrm{v})-303$ $\mathrm{K}, \sim 25 \mathrm{MPa}$. [Seabra et al, com permissão da Elsevier [60]]. 
A obtenção de extratos ricos em polifenóis, antocianinas e álcool perílico (com atividade anti-carcinogénica comprovada), foi também realizada de forma fracionada a partir de extração de cerejas (variedade saco, endémica de Portugal). A segunda etapa de extração (usando como solvente uma mistura de $\mathrm{CO}_{2}$ e EtOH) também originou extratos com maiores teores de compostos fenólicos, e um acréscimo de 10 a 100\% de etanol levou a um acréscimo considerável de antocianinas totais máximas com valores de $0.99 \mathrm{mg}$ de cyanidin-3-glucoside/g de extrato, para $100 \%$ de etanol pressurizado. As maiores atividades antioxidantes foram encontradas nos extremos das concentrações de etanol de 10 e 100\% (181 e $170 \mu \mathrm{mol}$ TEAC/g de extrato, respetivamente) provavelmente relacionada com os teores de compostos fenólicos e antocianinas presentes nos respetivos extratos. A maior atividade anti-proliferativa foi encontrada em extratos com etanol de 60 a 100\% [61] que pode estar relacionada à presença do álcool perílico e dos compostos fenólicos. A importância deste estudo foi reconhecida tendo este trabalho recebido o $1^{\circ}$ Prémio Nutrition Awards 2011, Categoria de Inovação e Desenvolvimento em Produtos e Serviços da Associação Portuguesa dos Nutricionistas/GCI, Portugal.

\subsection{Estudo do uso de misturas ternárias de solventes}

$\mathrm{O}$ uso de uma mistura de solventes (frequentemente $\mathrm{H}_{2} \mathrm{O}$ e EtOH) tem sido utilizado para atingir a máxima solubilidade/extração de antocianinas, uma vez que pequenas variações na polaridade do solvente tornam possível alterar a sua seletividade para estes compostos. Além disso, a acidificação do solvente é necessária para estabilizar estas moléculas e impedi-las de se oxidarem. Neste sentido a inserção de dióxido de carbono numa mistura de EtOH/ $\mathrm{H}_{2} \mathrm{O}$ promoverá a formação de ácido carbónico em pequenas quantidades, que podem ser suficientes para estabilizar as moléculas de antocianinas durante a extração. Assim, o estudo da extração destas moléculas foi realizado utilizando como solvente com mistura ternária de dióxido de carbono, etanol e água $\left(\mathrm{CO}_{2} / \mathrm{EtOH} / \mathrm{H}_{2} \mathrm{O}\right)$ a alta pressão e com temperatura (20.9 MPa e 313K) [51]. A composição 
das misturas de solvente varia desde proporções de 90:10:0 até 0:5:95, passando por várias composições em estado líquido e misturas de líquido-vapor. O rendimento das frações ricas em antocianinas é variável, sendo os maiores valores encontrados, de 20 a 24\%, obtidos com as misturas de solventes com composições 80/1/19, 60/8/32 e 0/20/80.
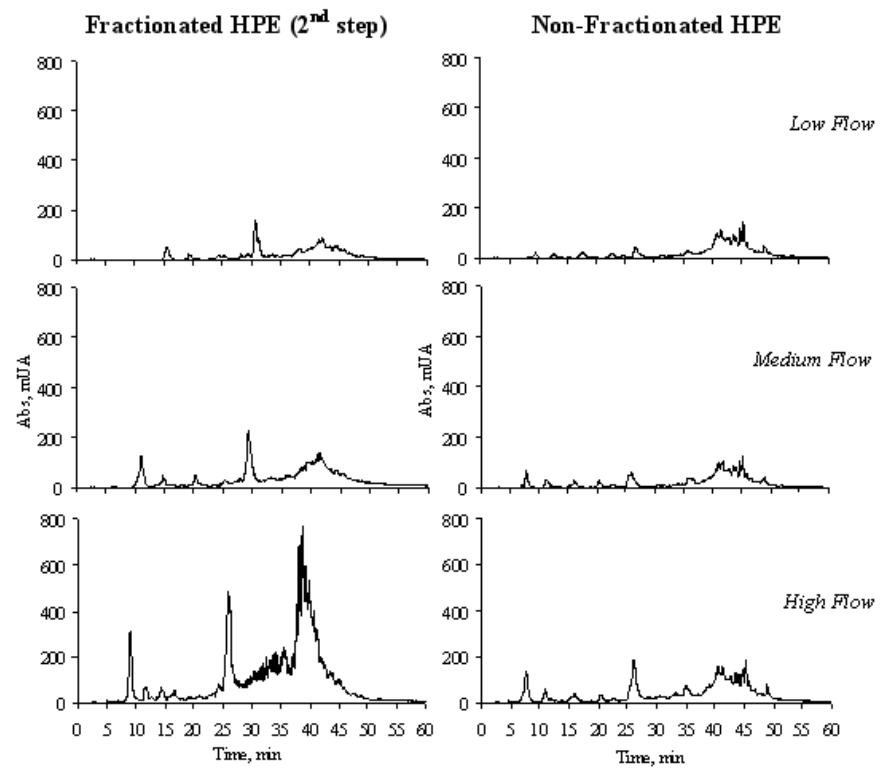

Figura 14.8. HPLC com fase reversa de extratos obtidos de casca de pinheiro marítimo utilizando o solvente $\mathrm{CO}_{2}$ : $\mathrm{EtOH}(90: 10)$ com diferentes caudais: baixo $\left(7.6 \times 10^{-5} \mathrm{~kg} / \mathrm{s}\right)$, médio $\left(13.2 \times 10^{-5} \mathrm{~kg} / \mathrm{s}\right)$ e alto $\left(19.1 \times 10^{-5} \mathrm{~kg} / \mathrm{s}\right)$. A concentração das amostras injetadas foi mantida constante e igual a $40 \mathrm{mg} / \mathrm{mL}$ [Seabra et al, com permissão da Elsevier [60]].

A tara (Caesalpinia spinosa), espécie nativa do Perú, tem sido utilizada na indústria do curtume pela sua composição em taninos hidrolisáveis. As sementes são fontes de galatomananas e utilizadas como agente espessante na indústria alimentar. Após o processamento do fruto restam ainda resíduos agro-industriais como a casca da semente utilizada para a obtenção das galatomananas. Este resíduo é abundante e foi explorado para identificar a possibilidade de obter extratos ricos em compostos polifenólicos com atividade antioxidante. Neste sentido, um desenho experimental foi proposto para otimizar a mistura de solventes 
a serem usados na extração seletiva de compostos fenólicos a partir da casca da semente dos frutos de tara. Tal como anteriormente, a mistura homogénea ternária de solventes envolveu o uso de etanol, água e dióxido de carbono. Esta mistura foi pressurizada e mantida em estado subcrítico a $313 \mathrm{~K}$ e $20 \mathrm{MPa}$ [62]. A Figura 14.9 apresenta o diagrama ternário de fases para a mistura de solventes proposta, onde se indicam as concentrações estudadas e a fase em que se encontram. A utilização de uma fase homogénea do solvente no sistema favorece a extração de compostos de forma também homogénea, evitando que o produto final possua uma grande variabilidade pela separação de fases dos solventes utilizados. Para os extratos ricos em compostos fenólicos foram realizadas análises de atividades antioxidante (medida pela oxidação acoplada de $\beta$-caroteno e ácido linoleico) e anti-inflamatória (medida pela inibição da atividade da lipoxigenase). Através de um modelo matemático linear para estudo do rendimento de extratos foi verificado que a água foi o solvente mais efetivo para o aumento do rendimento dos extratos. Um modelo quadrático indicou que a $\mathrm{H}_{2} \mathrm{O}$ e o $\mathrm{CO}_{2}$ tiveram um efeito antagónico, e que o teor máximo de compostos fenólicos foi obtido para misturas ricas em etanol. Por fim, um modelo cúbico indicou que a atividade anti-inflamatória máxima também foi obtida para misturas etanólicas. Os extratos revelaram também alta atividade antioxidante, igual a $80 \%$ e $70 \%$ após $3 \mathrm{~h}$ e $6 \mathrm{~h}$ de reacção, respetivamente. Desta forma, o extrato do resíduo do fruto da tara, tem grande potencial para ser valorizado tendo em conta as suas atividades antioxidante e anti-inflamatória, provavelmente relacionadas com a presença de compostos fenólicos existentes na espécie (Figura 14.10). 


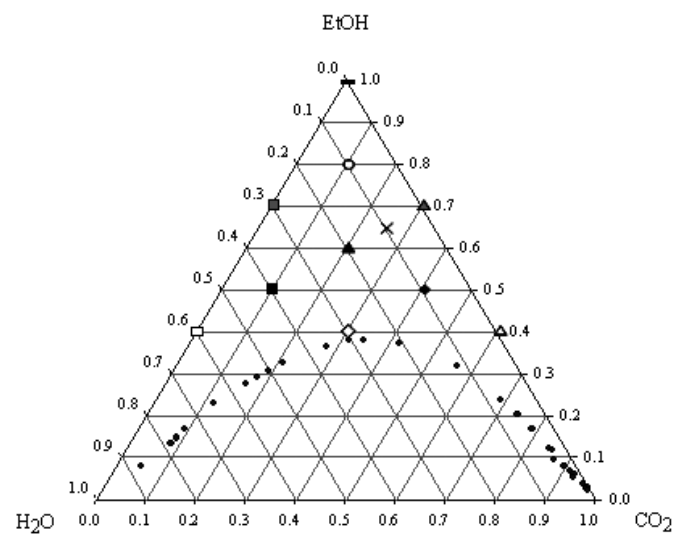

Figura 14.9. Representação da mistura de solvente utilizado com diversas frações molares de $\mathrm{CO}_{2}-\mathrm{EtOH}-\mathrm{H}_{2} \mathrm{O}: \square(0.0-0.4-0.6), \diamond(0.3-0.4-0.3), \Delta(0.6-0.4-0.0)$; (b) (0.1-0.5-0.4), $\boldsymbol{\Delta}(0.2-0.6-0.2), \diamond(0.4-0.5-0.1), \times(0.25-0.65-0.1), \bigcirc(0.1-0.8-0.1)$; (c) $\square(0.0-0.7-0.3), \Delta(0.3-0.7-0.0),-(0.0-1.0-0.0)$, e valores de equilíbrio de fases experimental para o sistema ternário a $313 \mathrm{~K}$ e $20 \mathrm{MPa},(\bullet)$.[Seabra et al, com permissão da Elsevier [62]].

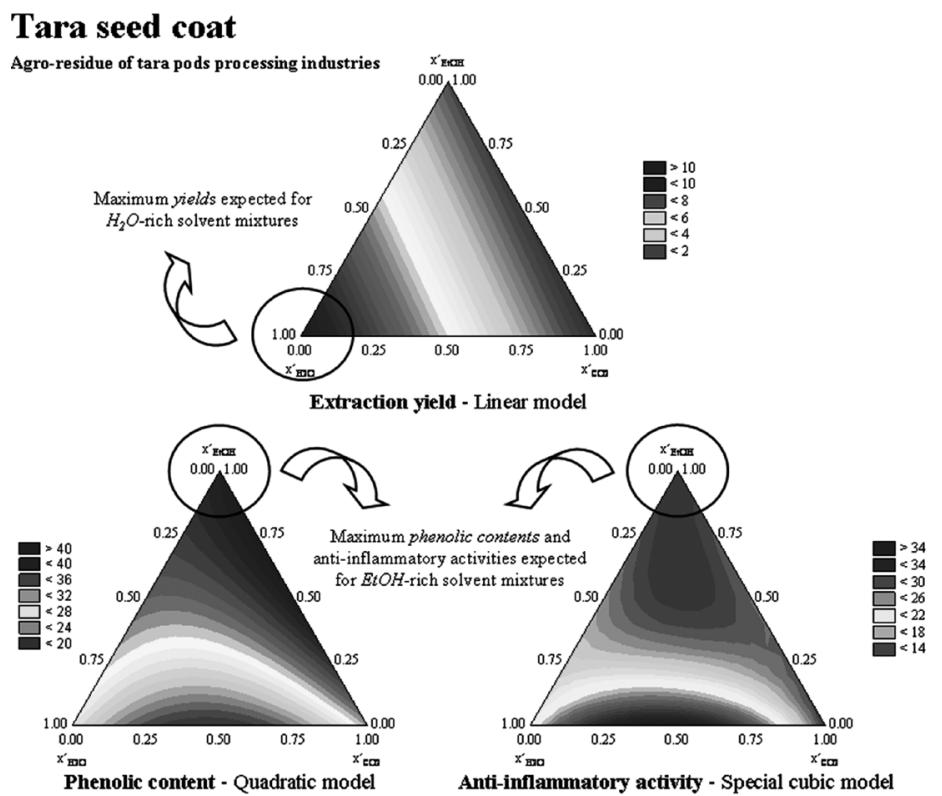

Figura 14.10. Resultados representados por curvas de superfícies de resposta para rendimento de extração, compostos fenólicos totais presentes nos extratos e valores de $\mathrm{IC}_{50}$ para extratos de casca da semente de tara obtidos por solvente pressurizado [Seabra et al, com permissão da Elsevier [62]]. 


\subsubsection{A matriz vegetal e a estratégia de extração}

Os compostos extratáveis de interesse podem estar contidos na superfície de uma folha ou no interior de um rizoma, e todo o processo de extração deve considerar os diferentes mecanismos envolvidos em cada caso por forma a otimizar o rendimento de extração [49]. A Figura 14.11 apresenta a estrutura secretora existente na superfície de uma folha de lipia (L. alba) observada por microscopia electrónica de varrimento, mostrando a sua morfologia e a presença de estruturas rompidas e in-

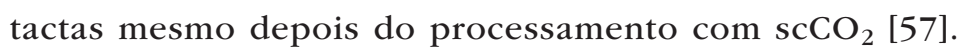
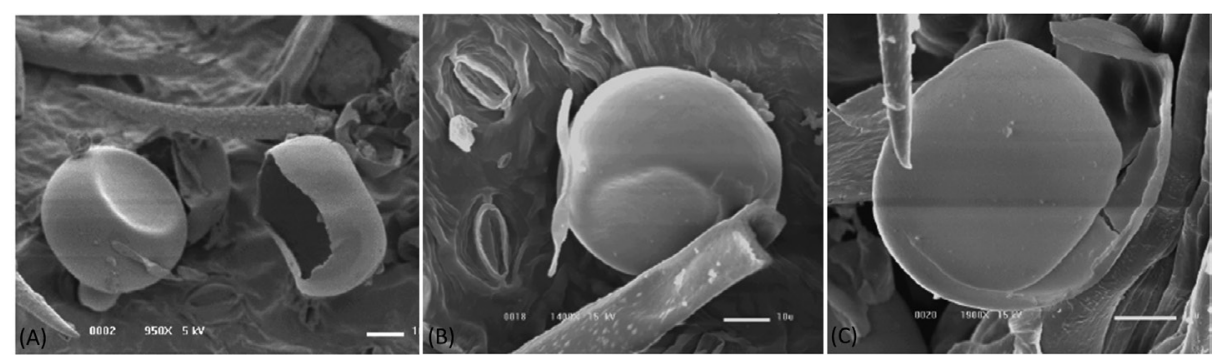

Figura 14.11. Estruturas secretoras da folha de lipia (L. alba) observadas por microscopia eletrónica de varrimento, $15 \mathrm{kV}$. (A) Estruturas intactas (esquerda) e rompidas (direita) antes da extração, (B) estruturas intactas depois da extração, e (C) estruturas rompidas depois da extração [Braga et al, com permissão da Elsevier [57]].

Este exemplo mostra a necessidade de optimização de condições de processo de extração por forma a esgotar o leito da matriz vegetal a ser estudada, sendo que estas condições são significativamente influenciadas pela natureza e composição da matriz vegetal. Os mecanismos de difusão do solvente no interior da matriz, que definem a eficiência da transferência de massa do processo, são certamente diferentes dependendo da estrutura da matéria prima a utilizar e que pode incluir cascas do tronco, cascas e sementes de frutos, rizomas, folhas, caules, flores ou misturas destas. Algumas estratégias de processamento a considerar que dependem do tipo de matriz a extrair incluem: o uso de co-solvente (diferentes tipos e concentrações) para extração (com ou sem fracionamento) de compostos 
de maior massa molecular (tal como já referido no item 14.2.2.2.1 onde foram focados os exemplos de matrizes como a casca de pinheiro [59, 60], o rizoma do açafrão [58, 63], a baga do fruto de sabugueiro [61, 64] e a casca da semente de tara [62] uso de um período estático no início do processo para matrizes com maior teor de fibras e amido, como o caso de cascas e rizomas, para garantir a difusão do solvente no interior da matriz; uso de temperaturas moderadas no caso de rizomas (e.x. açafrão e gengibre) para evitar reações indesejadas de hidrólise do amido e açúcares em presença de água ou garantir a presença de água na extração com $\mathrm{CO}_{2}$ para promover a formação de ácido carbónico e assim estabilizar ou tornar mais eficiente a extração de compostos sensíveis ao pH do meio (como é o caso das antocianinas).

Como caso de estudo refere-se a extração de espilantol a partir da espécie Spilanthes acmella, vulgarmente chamada de jambu e originária da Ásia e da América do Sul. O espilantol tem actividade analgésica e tem sido utilizado em tratamentos dentários como analgésico, apresentando também ação anti-microbiana, anti-inflamatória, diurética, vasorelaxante e antioxidante [65-68].

Neste estudo foram analisados as flores, folhas e caules de jambu separadamente, e para cada parte foi estudada uma primeira etapa de extracção com $\operatorname{scCO}_{2}$ puro, e sequencialmente uma segunda extracção, na matéria-prima deslipidificada, usando um co-solvente, como o etanol, a água ou a mistura destes dois. Os resultados mostraram a alta selectividade do $\mathrm{scCO}_{2}$ para a extração do espilantol, cerca de 65\% (b.s., quantificados por cromatografia gasosa, GC) (Figura 14.12), tendo-se identificado que a maior concentração deste composto se encontra na flor (confirmando o motivo do seu uso preferencial na medicina tradicional). Os extratos enriquecidos apresentaram uma atividade antioxidante relativamente elevada que foi associada à presença de compostos fenólicos no extrato, sendo a razão da actividade antioxidante pelo conteúdo total de compostos fenólicos de quase 93\%. Este mesmo extrato apresentou atividade anti-inflamatória acima de 50\%, para uma concentração de 20 $\mathrm{mg} / \mathrm{ml}$ quantificada através de um método indireto da inibição da atividade da enzima lipoxigenase [69]. 

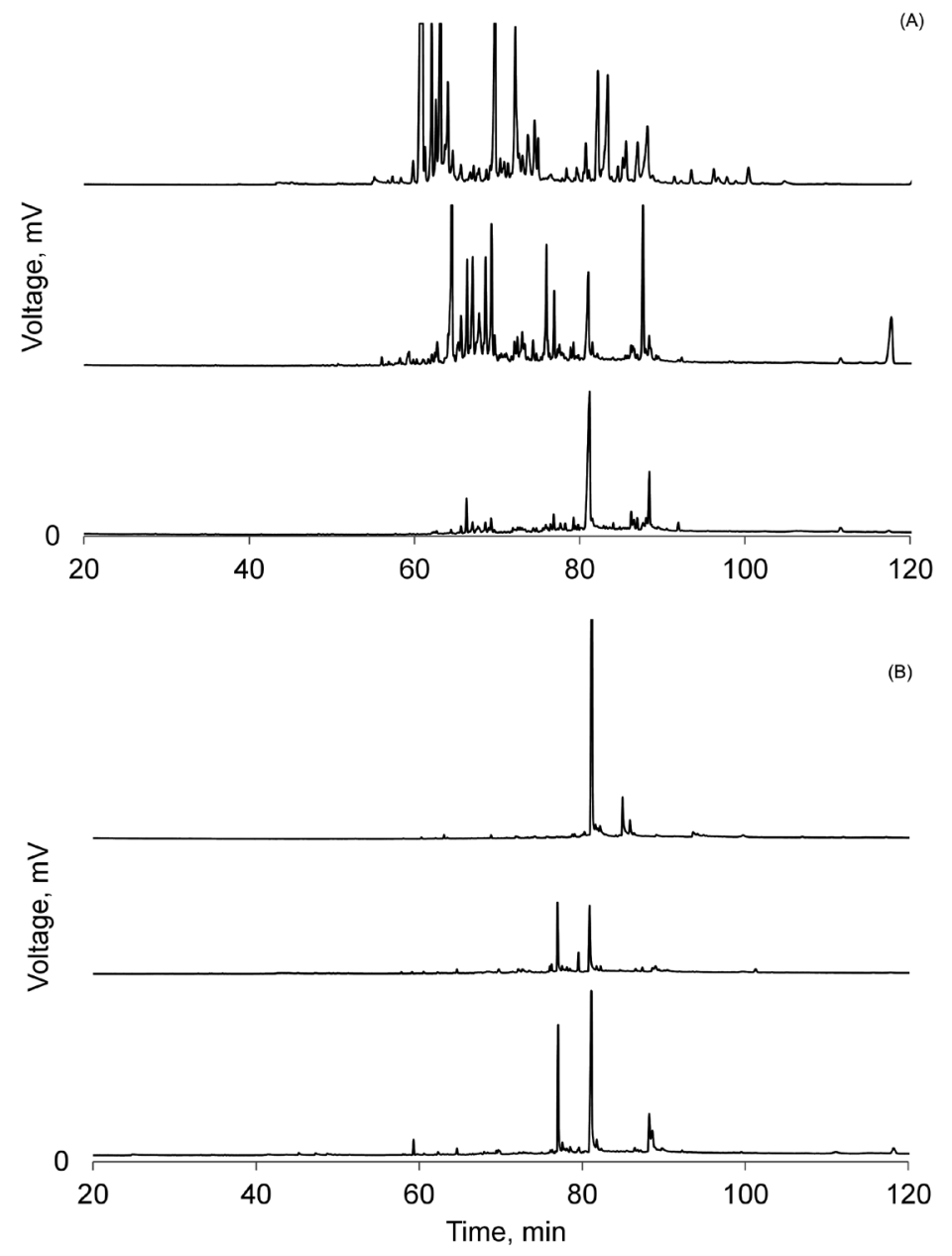

Figura 14.12. Cromatogramas (GC-FID) obtidos a partir da análise dos extratos de flores (posição superior), folhas (posição intermediária) e caules (posição inferior) de jambu utilizando o método da hidrodestilação (A) e o extração com $\operatorname{scCO}_{2}$ (B). [Dias et al, com permissão da Elsevier [69]].

14.2.2.4. Estudo da geometria do leito e modelação da cinética de extração

A otimização de parâmetros geométricos do sistema de extração, como por exemplo a razão altura/diâmetro do extrator, é outro 
fator a ser considerado por forma a maximizar os rendimentos de extração. A definição destes parâmetros permite ainda avaliar a possibilidade/vantagem de aumento de escala (scale-up) do processo. O estudo da influência deste parâmetro foi realizado por forma a maximizar a extração de curcuminóides a partir de curcuma tendo-se concluído que os melhores rendimentos para estes compostos bioativos foram obtidos com a menor razão altura/diâmetro estudada (igual a 1.8) [63]. A sobreposição das curvas cinéticas estudadas para as diferentes razões altura/diâmetro estudadas é uma indicação de que o controle do processo pode ser feito através das variáveis do processo (pressão, temperatura e caudal) por forma a aumentar a escala e manter a mesma resposta num processo industrial. Tendo em conta as vantagens anteriormente descritas, este estudo foi também feito com fracionamento do extrato constando de duas etapas, uma primeira $\mathrm{com} \mathrm{scCO}_{2}$ puro e uma segunda com uma mistura de $\mathrm{scCO}_{2}+$ etanol/isopropanol $(1: 1,50 \% \mathrm{v} / \mathrm{v})$. Os resultados mostram que as turmeronas e atlantonas continuam a ser extraídas no segundo passo, com concentração semelhante ao primeiro para as turmeronas e em maior quantidade para as atlantonas. A adição de co-solvente permite quadruplicar o rendimento da extração para os curcuminóides quando usado numa concentração superior a $50 \%$ (v/v) [63].

Estudos de efeito de escala foram também realizados por forma a otimizar a extração da cânfora, 1,8-cineol e ácido carnósico a partir de alecrim (Rosmarinus officinalis) usando $\mathrm{scCO}_{2}$ como solvente [70]. Estes compostos possuem atividades antioxidante, anti-inflamatória, anti-carcinogénica, analgésica e repelente [71]. Neste trabalho, diferentes modelos matemáticos foram estudados para descrever as cinéticas de extração, tendo os melhores ajustes sido obtidos pelos modelos de Goto, Sovová e Esquível [70]. Os modelos matemáticos auxiliam na predição dos valores de rendimento de extração ou de um composto puro, permitindo avaliar tendências e otimizar o processo de extração, além de auxiliar o aumento de escala do processo para equipamentos industriais. 


\subsection{Incorporação de compostos bioativos em matrizes poliméricas para aplicações biomédicas}

Após obtenção (extração e/ou separação) do composto, ou fração bioativa, a partir de determinada matriz vegetal é necessário avaliar a forma mais eficiente de aplicação do mesmo visando potenciar a sua ação (terapêutica ou outra). Algumas das questões mais importantes a considerar incluem a proteção da bioatividade do composto/extrato por tempo prolongado (evitando processos de oxidação e/ou degradação por radiação UV-Vísivel, térmica, etc) e o aumento da sua biodisponiblidade, idealmente de forma controlada, no que respeita a tempo de terapêutica e local de aplicação. Várias abordagens têm sido propostas por forma a atingir estes objetivos através de: i) encapsulamento dos compostos/extratos bioativos em matrizes poliméricas ou lipídicas [72-76]; ii) mistura (física) dos compostos/extratos bioativos com matrizes poliméricas orgânicas/inorgânicas e posterior processamento através de processos de evaporação, fusão, etc [77-78]; iii) absorção de soluções de compostos/extratos bioativos em matrizes poliméricas orgânicas/inorgânicas seguida da remoção dos solventes utilizados [77-78]; ou iv) impregnação dos compostos/extratos bioativos com matrizes poliméricas orgânicas/inorgânicas com fluidos supercríticos [63, 79-90].

Esta última abordagem tem sido aplicada pelo GSP para a impregnação de diferentes compostos bioativos sintéticos e de base natural, incluindo frações ativas de extratos obtidas também por extração supercrítica. Em seguida apresentam-se casos de estudo de impregnação de matrizes poliméricas, indicando vantagens do uso de processos integrados de extração e impregnação usando a mesma tecnologia, para o desenvolvimento de materiais para aplicação nas áreas médico-farmacêutica, cosmética e alimentar.

\subsubsection{Impregnação com $\mathrm{scCO}_{2}$}

A tecnologia de impregnação/deposição supercrítica (em inglês Supercritical Solvent Impregnation (SSI) ou Supercritical Solvent Deposition (SSD) apresenta as vantagens já referidas anteriormente considerando ainda 
que a utilização de $\mathrm{scCO}_{2}$ para impregnar matrizes poliméricas orgânicas/ inorgânicas tem o mesmo princípio da extração supercrítica no que se refere à solubilização de compostos que tenham afinidade com o solvente neste estado físico. Contudo neste caso é também de particular importância o tipo e força das interação que o $\mathrm{scCO}_{2}$ e o próprio extrato/fração bioativa podem estabelecer com a matriz de suporte e que vão condicionar o rendimento de impregnação (quantidade total de extrato/fração bioativa impregnada/ depositada na matriz) assim como a homogeneidade da dispersão do soluto na matriz (usando como vantagem a possibilidade de controlar a difusividade do $\mathrm{scCO}_{2}$ na matriz em função das condições de processamento).

Assim, o processo de impregnação é viável quando o composto(s) bioativo(s) é solúvel no fluido supercrítico e tem interação preferencial para a matriz sólida a impregnar onde fica retido após despressurização do sistema [91]. Durante o processo o polímero incha por ação do $\mathrm{scCO}_{2}$ (o que se traduz num efeito plastificante temporário) e o coeficiente de partição é favorável o suficiente para permitir que a matriz polimérica fique carregada com o soluto, ocorrendo uma dispersão molecular no interior do polímero, ou apenas adsorção à superfície da matriz (incluindo a superfície dos poros da matriz). A Figura 14.13 ilustra as interações que acontecem no sistema composto bioativo/matriz polimérica orgânica ou inorgânica/scCO $\mathrm{sCO}_{2}$. As condições de processamento (pressão, temperatura, tempo de contacto e taxa de despressurização) podem ser alteradas para aumentar a solubilidade do composto bioativo ou o grau de inchamento da matriz polimérica, o que permite ajustar o processo para cada sistema a ser produzido, obtendo-se desta forma matrizes diferenciadas, impregnadas com diferentes concentrações de composto bioativo.

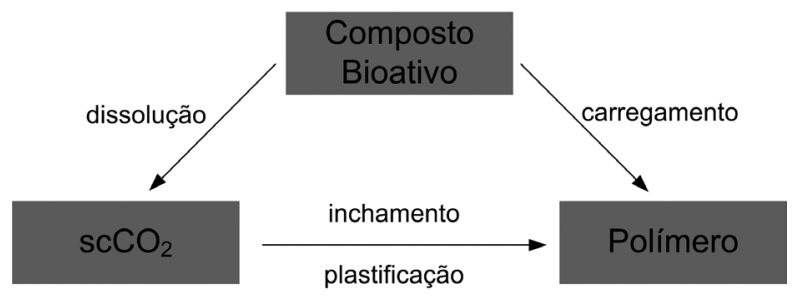

Figura 14.13. Interações entre os componentes de um sistema de impregnação utilizando $\mathrm{scCO}_{2}$, baseado em Kikic et al, 2003 [91]. 
Desta forma vários dispositivos previamente preparados (incluindo comercialmente disponíveis) podem ser posteriormente carregados não alterando assim o processo de fabricação destes, nem alterando as suas características originais [92].

A tecnologia supercrítica pode assim ser usada para simultaneamente extrair compostos de interesse de uma matriz vegetal e impregnar esses mesmos compostos numa matriz polimérica orgânica/inorgânica utilizando um único solvente, permitindo a integração de processos (o que pode levar à diminuição do custo do processo e do período de obtenção do mesmo) e mantendo as características de processo ambientalmente correto com utilização de solventes "verdes" e inertes [93].

Esta vertente tem sido também abordada pelo grupo de investigação GSP, que tem usado ambas as tecnologias, ainda que de forma independente, para o desenvolvimento de curativos para feridas à base de compostos bioativos e polímeros de base natural.

Neste âmbito, um caso de estudo recente consistiu no uso de um derivado de quitosano ( $N$-carboxibutilquitosano, CBC) como matriz sólida de suporte para o desenvolvimento de curativos bioativos após impregnação com quercetina e timol, compostos naturais que possuem atividade anti-inflamatória e analgésica, respetivamente [80]. A escolha do quitosano prende-se com o facto de ser um polímero usado para aplicações farmacêuticas (como scaffolds, hidrogéis, filmes, esponjas e fibras) devido à sua já provada biocompatibilidade, biodegradabilidade e atividades biológicas, nomeadamente anti-bacteriana e anti-fúngica (com mecanismos de atuação já reconhecidos), sendo aceite pelo FDA (Food and Drug Administration) para aplicações em pensos para feridas [94]. Além disso este biopolímero pode ser processado com $\mathrm{scCO}_{2}$ nas suas diversas formas, mantendo as suas características físico-químicas após o processamento. Neste trabalho, estudou-se a influência de condições de processamento (nomeadamante pressão e temperatura) na quantidade de compostos bioativos impregnados, assim como a influência da interação destes compostos com a matriz a impregnar, tendo-se usado a agarose como biopolímero de comparação. A Figura 14.14 apresenta a curva de libertação de cada uma das moléculas impregnadas a partir 
da $\mathrm{CBC}$, onde se verifica que o timol é libertado mais rapidamente (por ser uma molécula menor, e portanto com difusividade favorecida através da estrutura da CBC, e com maior solubilidade em água, usada como meio de liberação) enquanto que a quercetina apresenta uma taxa de liberação mais lenta e portanto mais controlada. A conjugação de duas moléculas com biodisponibilidades diferentes pode ser aplicada com a intenção de conjugar também as suas ações em benefício das necessidades do paciente. Desta forma a aplicação farmacêutica pode ser otimizada conseguindo-se uma ação analgésica imediata e uma ação anti-inflamatória prolongada no tempo.

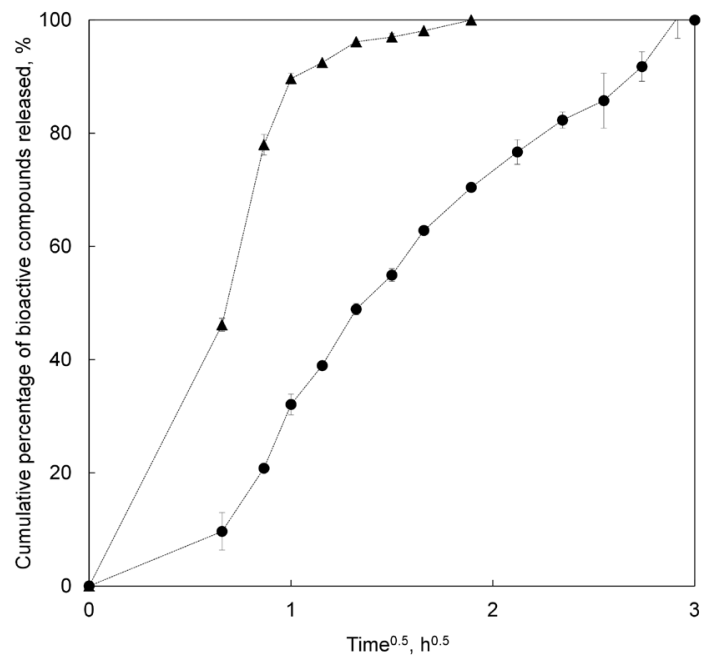

Figura 14.14. Gráfico de Higuchi para percentagem acumulada de libertação de compostos bioactivos. Espumas de CBC impregnadas com quercetina (•) e timol (A) a $20 \mathrm{MPa}$ e 323K [Dias et al, com permissão da Elsevier [80]].

Os resultados mostraram ainda que o processo de impregnação com $\mathrm{scCO}_{2}$ promoveu a micronização da quercetina (Figura 14.15), o que aumenta significativamente a solubilidade desta molécula em soluções aquosas e consequentemente a sua biodisponibilidade no organismo. Por fim foi ainda demonstrado que o processamento não afeta significativamente as propriedades físico-químicas e morfológicas da matriz de CBC e os sistemas preparados apresentaram adequada permeabilidade a oxigénio e vapor de água, com valores típicos e desejados para curativos utilizados em feridas. 

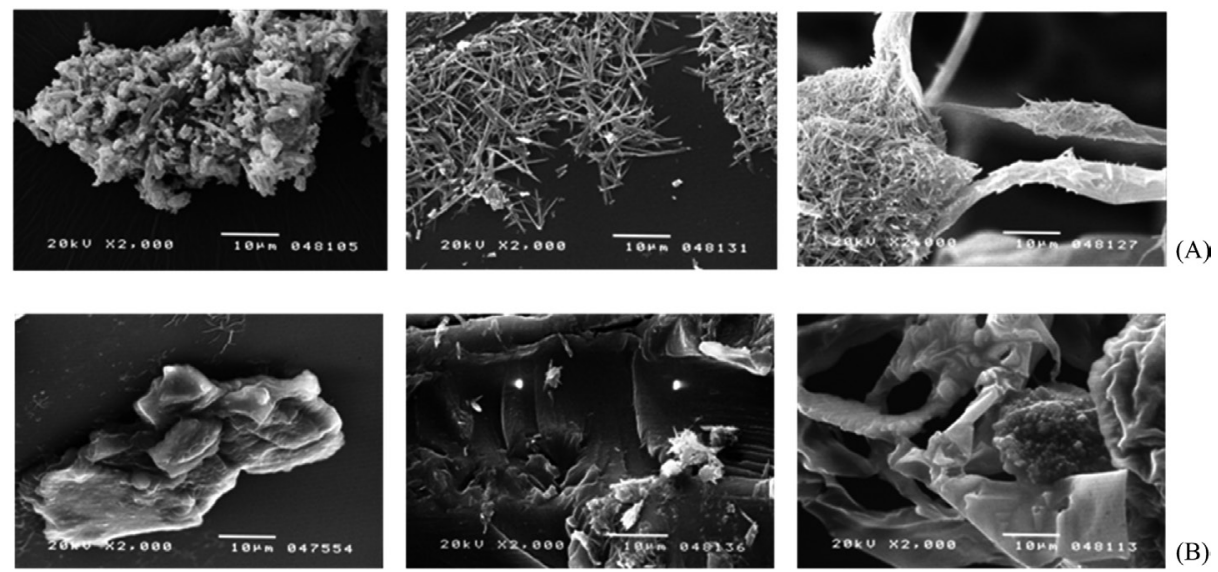

(B)

Figura 14.15. Microscopia electrónica de varrimento (SEM) para quercetina, timol para filmes e espumas de CBC. Amostras impregnadas $\mathrm{com} \mathrm{scCO}_{2}$ para quercetina (A) e para timol (B) a $20 \mathrm{MPa}$ e $323 \mathrm{~K}$. Da esquerda para a direita: compostos bioactivos não-processados, filmes de CBC impregnados e espumas de CBC impregnadas [Dias et al, com permissão da Elsevier] [80].

Um outro caso de estudo desenvolvido pelo grupo GSP consistiu na obtenção de um extrato com actividade anti-inflamatória, por extração de jucá (Libidibia ferrea) com $\mathrm{scCO}_{2}$, e posterior impregnação, usando o mesmo solvente, em diferentes matrizes poliméricas (comerciais e sintetizadas no laboratório) à base de quitosano, mistura de colágeno e dextrano oxidado e ácido hialurónico. A vantagem da impregnação do extrato em vez de compostos puros é que, sendo confirmada a bioatividade da fração (composta por uma mistura mais ou menos complexa de compostos diferentes), evitam-se procedimentos posteriores de separação e purificação de um composto em particular. Além disso em alguns casos os diferentes compostos presentes no extrato podem apresentar sinergismo o que potencia a ação do extrato comparativamente à ação de um composto puro. Devido à multiplicidade de compostos presentes na fração ativa torna-se particularmente importante a escolha da matriz a ser impregnada por forma a garantir que o coeficiente de partição matriz/scCO $\mathrm{seja}_{2}$ favorecido (tendo em conta que o extrato é solúvel em $\mathrm{scCO}_{2}$, uma vez que foi extraido com este solvente). De acordo com a Figura 14.16, os maiores rendimentos de impregnação foram obtidos usando a matriz de CBC (matriz 
sintetizada no laboratório) em comparação com as matrizes comerciais estudadas à base de colágeno e dextrano oxidado (Promogran ${ }^{\circledR}$ ) e ácido hialurónico (Hyalofill ${ }^{\circledR}$ ). Todos os materiais impregnados revelaram ser citocompatíveis e apresentaram atividade anti-inflamatória quando testado em macrófagos. Tendo em conta a composição química do extrato é de prever que esta atividade seja promovida por compostos terpénicos (como o sitosterol e/ou a lupenona) e/ou ácidos gordos insaturados (como os ácidos linoléico, palmítico e esteárico) presentes na fração de extrato de jucá estudada [85].

Nos últimos anos a tecnologia de impregnação supercrítica tem sido cada vez mais usada e para diferentes aplicações, principalmente na área médico-farmacêutica e alimentar, devido às características vantajosas anteriormente referidas (ver referências indicadas no Capítulo 8 deste livro). A impregnação de compostos puros ou frações ativas de origem natural tem tido um crescimento mais acentuado apenas nos últimos anos, provavelmente devido à complexidade acrescida de análise e de numerosos parâmetros a otimizar (principalmente no caso de frações compostas por mais do que um componente), mas também devido à dificuldade acrescida na legislação dos produtos finais obtidos. Contudo, é de esperar que o crescente número de trabalhos publicados na área e o conhecimento mais aprofundado dos fenómenos envolvidos, assim como em técnicas de caracterização capazes de comprovar de forma efetiva a vantagem do processo, venha a facilitar/acelerar o processo de regulamentação, e assim a aplicabilidade da técnica à escala industrial. Alguns casos de sucesso já reportados na literatura incluem, na área biomédica, a impregnação de artimisinina em derivados de quitosano para o tratamento de malária [79] e de timol em gaze de algodão para tratamento de feridas [86] na área alimentar, a impregnação de timol em filmes de LLDPE [89] e de amido [90] para o desenvolvimento de embalagens com atividade anti-microbiana ou de ácido oleico em partículas de amido [82] e $\beta$-caroteno em poli-( $\varepsilon$-caprolactona) [87] para liberação controlada de nutracêuticos. Alguns exemplos de estudos de impregnação de frações bioativas (com solubilidade elevada em $\mathrm{scCO}_{2}$ ) em matrizes poliméricas já reportados na literatura incluem a impregnação de óleo essencial de 
lavanda (com atividade biocida) em amido modificado [81], de óleo de cipreste (com atividade repelente) em copolímeros à base de ácido lático [83], de óleo de linho em aerogéis de um polissacarídeo da cevada [84] e de óleo essencial de orégão em amido [88] visando proteger a capacidade antioxidante destes óleos por períodos de tempo mais prolongados na indústria alimentar.

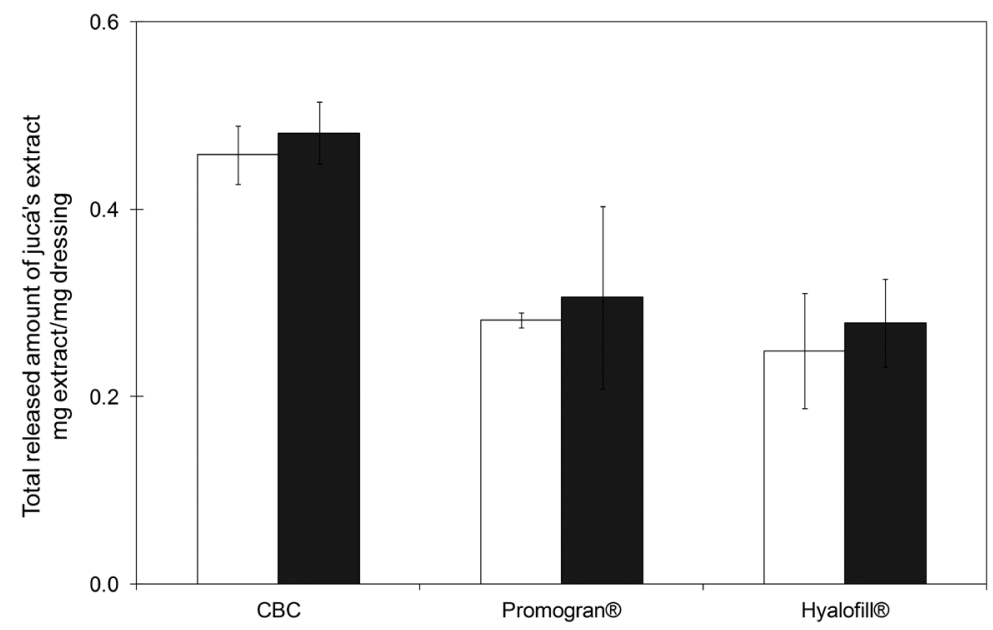

Figura 14.16. Massa de extrato de jucá impregnada em diferentes matrizes poliméricas (a $27 \mathrm{MPa}$ e $50{ }^{\circ} \mathrm{C}$ ). Taxa de despressurização a $3 \mathrm{MPa} \min ^{-1}$ (匹) e 10

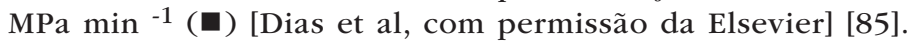

\subsection{Conclusões}

Com este capítulo pretendeu-se apresentar de forma resumida algumas das estratégias que o grupo de investigação do Laboratório de Processos Verdes e Sustentáveis, do Centro de Investigação em Engenharia dos Processos Químicos e dos Produtos da Floresta do Departamento de Engenharia Química da Universidade de Coimbra, tem aplicado com o objetivo de extrair e caracterizar compostos bioativos (compostos puros ou frações constituídas por misturas de vários compostos) a partir de diferentes matrizes vegetais (destacando-se a valorização de resíduos 
agro-industriais e renováveis) que podem ser aplicados como suplementos alimentares, fitoterápicos, nutracêuticos, cosméticos ou pesticidas naturais.

O capítulo começa por reforçar a importância do uso de fitoquímicos (compostos bioativos produzidos pelo metabolismo secundário das plantas para proteção) tendo em conta a sua enorme biodisponibilidade, variedade e grande diversidade de benefícios que apresentam para a saúde humana. Refere-se ainda o longo percurso necessário para que um fitoquímico dê origem a um fitoterápico (medicamento obtido exclusivamente a partir de matérias-primas ativas vegetais) o que implica o conhecimento da eficácia e dos riscos de seu uso (obtidos numa primeira fase através de levantamentos etnofarmacológicos de utilização), assim como da reprodutibilidade da sua qualidade e da sua ação.

Em seguida refere-se a vantagem do uso da tecnologia de fluidos supercríticos para a extração, fracionamento, separação e/ou isolamento deste tipo de compostos principalmente quando se pretende a sua aplicação na indústria medico-farmacêutica ou alimentar tendo em conta o caráter não tóxico dos solventes usados com esta tecnologia (ausência de traços de solventes orgânicos tóxicos nas fracções obtidas e redução de etapas posteriores de fraccionamento). Além disso, e através da correta otimização de diferentes variáveis de processo, é possível aumentar a eficiência e seletividade do processo para determinado composto (ou fração bioativa) alvo. Entre as variáveis de processo normalmente variadas, e referidas neste capítulo, destacam-se o estudo das condições ótimas de pressão e temperatura de processamento; o efeito dos co-solventes e do caudal de solvente (ou mistura de solventes) no rendimento de extração e no fracionamento do extrato; a influência da matriz vegetal (tipo e composição) na estratégia de extração a usar e a importância do estudo da geometria do leito e modelação da cinética de extracção para efeito de aumento de escala e valorização económica do processo. Por fim descreve-se o uso da tecnologia de fluidos supercríticos como processo eficiente e seguro para impregnar/depositar os compostos bioativos extraídos de matrizes vegetais em matrizes poliméricas por forma a prolongar a sua bioatividade e controlar a sua libertação no meio em que se pretende que atuem. 
Apesar de serem tecnologias ainda relativamente recentes, espera-se que as vantagens da extração e impregnação/deposição usando fluidos supercríticos permitam, num futuro próximo, reduzir custos inerentes ao processo de desenvolvimento de novos fármacos ou dispositivos médico-farmacêuticos através da otimização das tecnologias e integração de processos (extração/impregnação), com o objetivo de desenvolver produtos de base natural mais eficientes e sustentáveis para a prevenção ou cura de problemas de saúde de amplo espectro deste indução de efeito analgésico até ao tratamento do cancro. A simplificação do processo de desenvolvimento de produtos médico-farmacêuticos de origem natural e redução de custos associados ao processo podem trazer novas perspectivas para países com poucos recursos económicos aplicados à assistência social da população carenciada.

\subsection{Agradecimentos}

Os autores agradecem o apoio de: FCT-MCTES/MEC, FUP, FEDER, COMPETE, Programa Ciência 2008 (Portugal), CAPES (Brasil), e Rede CYTED, através dos contratos: PEst-C/EQB/UI0102/2011, PEst-C/EME/ UI0285/2013, POCTI/FCB/38213/2001, PTDC/SAU-BEB/71395/2006, PTDC/ SAU-FCF/71399/2006, Acções Integradas Luso-Espanholas 2010 Ref. E-7/10, Cooperação Científica e Tecnológica FCT/CAPES 2011/2012 Ref. 4.4.1.00, e Rede "RIMADEL - Rede Iberoamericana de Nuevos Materiales para el Diseño de Sistemas Avanzados de Liberación de Fármacos en Enfermidades de Alto Impacto Socioeconómico". Mara E.M. Braga e Ana M.A. Dias agradecem ainda à FCT.MCTES/MEC as bolsas de pós-doutoramento SFRH/ BPD/21076/2004 e SFRH/BPD/40409/2007.0

\subsection{Bibliografia}

[1] R.Verpoorte, H.K. Kim, Y.H. Choi, In: Medicinal and Aromatic Plants, R.J. Bogers, L.E. Craker and D.Lange (eds.). Springer. Chapter 19, 261-273, 2006.

[2] S. D. Sarker, Z. Latif, A. I. Gray. Natural Products Isolation. 2nd ed. Humana Press 2006. 
[3] F. Watkins, B. Pendry, A. Sanchez-Medina, O. Corcoran. J. Ethnopharmacol. 2012, 144, 408-41.

[4] M.G.L. Brandão, N.N.S. Zanetti, P. Oliveira, C.F.F. Grael, A.C.P. Santos, R.L.M. Monte-Mór J. Ethnopharmacol. 2008, 120, 141-148.

[5] B.E. Van Wyk. South African J. Botany, 2011, 77, 812-829.

[6] A. Pieroni, H. Muenz, M. Akbulut, K.H.C. Baser, C. Durmuskahya. J. Ethnopharmacol. 2005, 102, 69-88.

[7] A. Pieroni. J. Ethnopharmacol. 2000, 70, 235-273.

[8] P. J. De Vos. Ethnopharmacol. 2010, 132, 28-47.

[9] I. Siró, E. Kapolna, B. Kapolna, A. Lugasi. Appetite, 2008, 51, 456-467.

[10] E. Antignac, G.J. Nohynek, T. Re, J. Clouzeau, H. Toutain. Food Chem. Toxicol. 2011, 49, 324-341.

[11] E. Panagiotakopulu, P.C. Buckland, P.M. Day, A.A. Sarpaki, C. Doumas. J.Archaeol. Sci. 1995, 22, 705-710.

[12] R.F. Bast, P.C. Chandler, L.M. Choy, J. Delmulle, S.B.A. Gruenwald, K.K. Halkes, J.H. Koeman, P. Peters, H. Przyrembel, E.M. de Ree, A.G. Renwick, I.T.M. Environ.Toxicol. Pharmacol. 2002, 12, 195-211.

[13] A.Gurib-Fakim. Mol. Asp. Med. 2006, 27, 1-93.

[14] N.G. Asp, S. Bryngelsson. J. of Nutrition, Health claims in Europe, 2008, 1210-1215 Supplement.

[15] P. Coppens, L. Delmulle, O. Gulati, D. Richardson, M. Ruthsatz, H. Sievers, S. Sidani. Ann. Nutr. Metab. 2006a, 50, 538-554.

[16] P. Coppens, M.F. da Silva, S. Pettman. Toxicology, 2006b, 221, 59-74.

[17] O.P.Gulati, P.B. Ottaway. Toxicology, 2006, 221, 75-87.

[18] Food and Drug Administration (FDA) U.S. Department of Health and Human Services, Center for Drug Evaluation and Research (CDER), Chemistry. Guidance for Industry BotanicalDrugProducts,2004.www.fda.gov/downloads/Drugs/GuidanceCompliance RegulatoryInformation/Guidances/UCM070491.pdf (accessed July 15, 2014).

[19] D.J. Newman, G.M. Cragg, K.M. Snader. J. Nat. Prod. 2003, 66, 1022-1037.

[20] M. Giorgetti, G. Negri, E. Rodrigues. J. Ethnopharmacol. 2007, 109, 338-347.

[21] H. De Wet, V.N. Nzama, S.F. Van Vuuren. Afr. J. Bot. 2012, 78, 12-20.

[22] M. Adams, S.V. Schneider, M. Kluge, M. Kessler, M. Hamburger. J. Ethnopharmacol. 2012, 143, 1-13.

[23] G.J. Martínez. Midwifery, 2008, 24, 490-502.

[24] G.A. Wachter, S. Valcic, M.L. Flagg, S.G. Franzblau, G. Montenegro, E. Suarez, B.N. Timmermann. Phytomedicine, 1999, 6, 341-345.

[25] B. Saric-Kundalic, C. Dobes, V. Klatte-Asselmeyer, J. Saukel. J. Ethnopharmacol. 2010, $131,33-55$.

[26] M. Giorgetti, G. Negri, E. Rodrigues. J. Ethnopharmacol. 2007, 109 338-347.

[27] M.F.T. Medeiros, U.P. de Albuquerque. J. Ethnopharmacol. 2012, 139, 280- 286.

[28] M.H. Yin, D.G. Kang, D.H. Choi, T.O. Kwon, H.S. Lee. J. Ethnopharmacol. 2005, 99, 113-117.

[29] V. Tene, O. Malagon, P.V. Finzi, G. Vidari, C. Armijos, T. Zaragoza. J. Ethnopharmacol. 2007, 111, 63-81. 
[30] A.R. Bilia, S.Gallori, F.F. Vincieri. Life Sciences, 2002, 70, 3077-3096.

[31] G. Benítez. Andalusia (Spain). J. Ethnopharmacol. 2011, 137, 1113-1123.

[32] Kumar, A. Kumar, O. Prakash. J. Ethnopharmacol. 2012, 140, 1-32.

[33] B. Kumar, M. Vijayakumar, R. Govindarajan, P. Pushpangadan. J. Ethnopharmacol. 2007, 114, 103-113.

[34] T. Thirumalai, B.C. David, K. Sathiyaraj, B. Senthilkumar, E. David. Asian Pac. J. Trop. Biomed. 2012, S910-S913.

[35] A. Pollio, A. De Natale, E. Appetiti, G. Aliotta, A. Touwaid. J. Ethnopharmacol. 2008, 116, 469-482.

[36] M.R. Gonzalez-Tejero, M. Casares-Porcel, C.P. Sanchez-Rojas, J.M. Ramiro-Gutierrez, J. Molero-Mesa, A. Pieroni, M.E. Giusti, E. Censorii, C. de Pasquale, A. Della, D. Paraskeva-Hadijchambi, A. Hadjichambis, Z. Houmanie, M. El-Demerdash, M. El-Zayat, M. Hmamouchi, S. ElJohri. J. Ethnopharmacol. 2008, 116, 34-357.

[37] M. Leonti, O. Sticher, M. Heinrich. J. Ethnopharmacol. 2003, 88, 119-124.

[38] M.H. Li, Y. Liu, Z.W. Wang, Cui, L.Q. Huang, P.G. Xiao. Chinese Herbal Medicines, 2012, 2, 301-313.

[39]. L.P. Kvist, S.B. Christensen, H.B. Rasmussen, K. Mejia, A. Gonzalez. J. Ethnopharmacol. 2006, 106, 390-402.

[40] X. Jauregui, Z.M. Clavo, E.M. Jovel, M. Pardo-de-Santayana. J. Ethnopharmacol. 2011, $134,739-752$.

[41] E.A. Goun, V.M. Petrichenko, S.U. Solodnikov, T.V. Suhinina, M.A. Kline, G. Cunningham, C. Nguyen, H. Miles. J. Ethnopharmacol. 2002, 81, 337-342.

[42] K. Savikin, G. Zdunic, N. Menkovic, J. Zivkovic, N. Cujic, M. Terescenko, D. Bigovic. J. Ethnopharmacol. 2013, 146, 803-810.

[43] K.Srithi, C.Trisonthi, P. Wangpakapattanawong, H. Balslev. J. Ethnopharmacol. 2012, 139, 119-135..

[44] V. Lipipun, M. Kurokawa, R. Suttisri, P. Taweechotipatr, P. Pramyothin, M. Hattori, K. Shiraki Antiviral Res. 2003, 60, 175-180.

[45] S. Voravuthikunchai, A. Lortheeranuwat, W. Jeeju, T. Sririrak, S. Phongpaichit, T. Supawita. J. Ethnopharmacol. 2004, 94, 49-54.

[46] U. Cakilcioglu, I. Turkoglu. J. Ethnopharmacol. 2010, 132, 165-175.

[47] Q. Le Tran, Y. Tezuka, J. Ueda, N.T. Nguyen, Y. Maruyama, K. Begum, H.S. Kim, Y. Wataya, Q.K. Tran, S. Kadota. J. Ethnopharmacol. 2003, 86, 249-252.

[48] E. Talansier, M.E.M. Braga, P.T.V. Rosa, D. Paolucci-Jeanjean, M.A.A. Meireles. J. of Supercritical Fluids, 2008, 47, 200-208.

[49] M.E.M. Braga, I.J. Seabra, A.M.A. Dias, H.C. de Sousa. In: Natural Products Extraction: Principles and Applications, Royal Society of Chemistry (RSC Publishing), M. Rostagno and J. Prado (Eds), Chapter 7, 231-284, 2013.

[50] M. Mukhopadhyay. Natural Extracts Using Supercritical Carbon Dioxide. CRC Press, 2000.

[51] I.J. Seabra, M.E.M. Braga, M.T. Batista, H.C. de Sousa. J. Supercrit. Fluids, 2010, 54, 145-152.

[52] T. Norton, D.W. Sun. Food Bioprocess Tech. 2008, 1, 2-34.

[53] M.A.A. Meireles (Ed.), Extracting bioactive compounds: theory and applications, on the Contemporary Food Engineering book series, organized by Professor Da-Wen Sun, National University of Ireland, Dublin. CRC press, Taylor and Francis, 2009. 
[54] P.T.V. Rosa, M.A.A. Meireles. J. Food Eng. 2005, 67, 235-240.

[55] C.L.C. Albuquerque, M.A.A Meireles. J. Supercrit. Fluids, 2012, 66, 86-95.

[56] A.M. Farías-Campomanes, M.A. Rostagno, M.A.A. Meireles. J. Supercrit. Fluids, 2013, 77, 70-78.

[57] M.E.M. Braga, Ehlert, P.A.D.; Ming, L.C.; Meireles, M.A.A. J. Supercrit. Fluids, 2005, 34, 149-156.

[58] M.E.M. Braga, P.F. Leal, J.E. Carvalho, M.A.A. Meireles. J. Agri. Food Chem. 2003, 51, 6604-6611.

[59] M.E.M. Braga, R. Santos, I. Seabra, H.C. De Sousa. J. Supercrit. Fluids, 2008, 47, 37-48.

[60] I.J. Seabra, A.M.A. Dias, M.E.M. Braga, H.C. De Sousa. J. Supercrit. Fluids, 2012a, 62, 135-148.

[61] A.T. Serra, I.J. Seabra, M.E.M. Braga, M.R. Bronze, H.C. De Sousa, C.M.M. Duarte. J. Supercrit. Fluids, 2010, 54, 184-191.

[62] I.J. Seabra, M.E.M. Braga, H.C. de Sousa. J. Supercrit. Fluids, 2012b, 64, 9-18.

[63] M.E.M. Braga, M.A.A. Meireles. J. Food Process Eng., 2007, 30, 501-521.

[64] I.J. Seabra, A.M.A. Dias, M.E.M. Braga, H.C. De Sousa. J. Supercrit. Fluids, 2010, 54, 145-152.

[65] L. Jirovetz, G. Buchbauer, G.T. Abraham, M.P. Shafi. Flavour Frag. J. 2006, 21, 88-91.

[66] J. Boonen, B. Baert, N. Roche, C. Burvenish, B. De Spiegeleer. J. Ethnopharmacol. 2010, 127 77-84.

[67] W.D. Ratnasooriya, K.P.P. Pieris, U. Samaratunga, J.R.A.C. Jayakody. J. Ethnopharmacol. 2004, 91, 317-320.

[68] O. Wongsawatkul, S. Prachayasittikul, C.I. Ayudhya, J. Satayavivad, S. Ruchirawat, Int. J. Molecular Sci. 2008, 9, 2724-2744.

[69] A.M.A. Dias, P. Santos, I. J. Seabra, R. N. C. Júnior, M. E. M. Braga, H. C. de Sousa, J. Supercrit. Fluids, 2012, 61, 62-70.

[70] R.N. Carvalho, L.S. Moura, P.T.V. Rosa, M.A.A. Meireles. J. Supercrit. Fluids, 2005, 35, 197-204.

[71] V.G. Kontogianni, G. Tomic, I. Nikolic, A.A. Nerantzaki, N. Sayyad, S. Stosic-Grujicic, I. Stojanovic, I.P. Gerothanassis, A.G. Tzakos. Food Chem. 2013, 136, 120-129.

[72] M.P. Souza, A.F.M. Vaz, M.T.S. Correia, M.A. Cerqueira, A.A. Vicente, M.G. Carneiro-da-Cunha. Food Bioprocess Technol. 2014, 7, 1149-1159.

[73] D.F. Cortés-Rojas, C.R.F. Souza, W.P. Oliveira. J.Food Eng. 2014, 127, 34-42.

[74] E. Pinho, M. Grootveld, G. Soares, M. Henriques. Carbohydr. Polym. 2014, 101, 121-135.

[75] D. Hennig, S. Schubert, H. Dargatz, E. Kostenis, A. Fahr, U.S. Schubert, T. Heinzel, D. Imhof. Macromol. Biosci. 2014, 14, 69-80.

[76] E. Mascheroni, C.A. Fuenmayor, M.S. Cosio, G. Di Silvestro, L. Piergiovanni, Mannino, S., A. Schiraldi. Carbohydr. Polym. 2013, 98, 17-25.

[77] E. M. Hoepfner, S. Lang, A. Reng, P.C. Schmidt, (Eds.), Fiedler encyclopedia of excipients: for pharmaceuticals, cosmetics and related areas, Buch + CD-ROM, Editio Cantor, 2007.

[78] S.K. Niazi, (Ed.), Handbook of Pre-Formulation: Chemical, Biological, and Botanical Drugs, CRC Press, 2006.

[79] M.E.M. Braga, M.S. Ribeiro, M.H. Gil, H.S.R. Costa Silva, E.I. Ferreira, H.C. de Sousa. Proceedings of the 2007 AIChE Annual Meeting, Salt Lake City, Utah, USA, November 4-9, 2007. 
[80] A.M.A. Dias, M.E.M. Braga, I.J. Seabra, P. Ferreira, M.H. Gil, H.C. de Sousa. Int. J. Pharm. 2011, 408, 9-19.

[81] S. Varona, S. Rodríguez-Rojo, A. Martín, M.J. Cocero, C.M.M. Duarte. J. Supercrit. Fluids 2011, 58, 313-319.

[82] L.M. Comin, F. Temelli, M.D.A. Saldaña. J. Supercrit. Fluids, 2012, 61, 221-228.

[83] C. Tsutsumi, T. Hara, N. Fukukawa, K. Oro, K. Hata, Y. Nakayama, T. Shiono. Green Chem. 2012, 14, 1211-1219.

[84] L.M. Comin, F. Temelli, M.D.A. Saldaña. J. Food Eng. 2012, 111, 625-631.

[85] A.M.A. Dias, A. Rey-Rico, R.A. Oliveira, S. Marceneiro, C. Alvarez-Lorenzo, A. Concheiro, R.N. Carvalho Júnior, M.E.M. Braga, H.C. de Sousa. J. Supercrit. Fluids, 2013, 74, 34-45.

[86] S. Milovanovic, M. Stamenic, D. Markovic, M. Radetic, I. Zizovic. J. Supercrit. Fluids, 2013, 84, 173-181.

[87] E. Paz, S. Rodríguez, J. Kluge, A. Martín, M. Mazzotti, M.J. Cocero. J. Supercrit. Fluids, 2013, 84, 105-112.

[88] A.P. Almeida, S. Rodríguez-Rojo, A.T. Serra, H. Vila-Real, A.L. Simplício, I. Delgadilho, S.B. da Costa, L.B. da Costa, I.D. Nogueira, C.M.M. Duarte. Innov. Food Sci. Emerg. Technol. 2013, 20, 140-145.

[89] A.Torres, J. Romero, A. Macan, A. Guarda, M.J. Galotto. J. Supercrit. Fluids, 2014, 85, $41-48$.

[90] A.C. Souza, A.M.A. Dias, H.C. de Sousa, C.C. Tadini. Carbohydr. Polym. 2014, 102, 830-837.

[91] I. Kikic, F. Vecchione. Curr. Opin. Solid State Mater. Sci. 2003, 7, 399-405.

[92] M.E.M. Braga, V.P. Costa, M.J.T. Pereira, P.T. Fiadeiro, A.P.A.R. Gomes, C.M.M. Duarte, H.C. De Sousa. Int. J. Pharm. 2011, 420, 231-243.

[93] M.A. Fanovich, J. Ivanovic, D. Misic, M.V. Alvarez, P. Jaeger, I. Zizovic, R. Eggers, J. Supercrit. Fluids, 2013, 78, 42-53.

[94] F. Croisier, C. Jérôme. Eur. Polym. J. 2013, 49, 780-792. 